
de Mestre em Engenharia. 


\section{SEGMENTAÇÃO E DETECÇÃO DE SIMETRIA EM IMAGENS VIA REDES DE MAPAS ACOPLADOS}

Dissertação apresentada à Escola Politécnica da Universidade São Paulo para obtenção do Título de Mestre em Engenharia.

Área de concentração:

Engenharia de Sistemas

Orientador:

Luiz Henrique Alves Monteiro 
Este exemplar foi revisado e alterado em relação à versão original, sob responsabilidade única do autor e com a anuência de seu orientador

São Paulo, 26 de fevereiro de 2007

Assinatura do autor

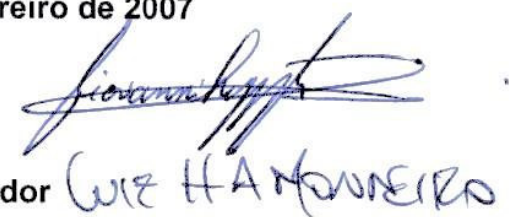

Assinatura do orientador

\section{FICHA CATALOGRÁFICA}

Rizzo Junior, Giovanni

Segmentação e detecção de simetria em imagens via redes de mapas acoplados / Giovanni Rizzo Junior - ed. rev. - São Paulo, 2006.

$76 \mathrm{p}$.

Dissertação (Mestrado) - Escola Politécnica da Universidade de São Paulo. Departamento de Engenharia de Telecomunicações e Controle.

1.Processamento de imagens 2.Sistemas dinâmicos 3. Redes de mapas acoplados I.Universidade de São Paulo. Escola Politécnica. Departamento de Engenharia de Telecomunicações e Controle II.t. 
Aos meus pais. 


\section{Agradecimentos}

Primeiramente devo agradecer ao meu orientador, Luiz Henrique Alves Monteiro, pela disponibilidade, sendo sempre acessível e paciente, pelos conselhos valiosos e construtivos, compreensão e ajuda sincera nos momentos difíceis pelo qual minha vida pessoal atravessou neste período, e pela conciliação de permitir e estimular a liberdade de criação com a responsabilidade do espírito crítico. Obrigado por tudo, amigo.

Agradeço também a todos os professores e colegas, que contribuíram e incentivaram a realização desta dissertação, durante o tempo em que estudei no curso de pós-graduação. Em especial agradeço aos professores José Roberto Castilho Piqueira, Emílio Del Moral Hernandez, Oswaldo Luiz do Valle Costa, Fuad Kassab Junior, José Aquiles Baesso Grimoni, Osvaldo Nakao e Maria das Dores dos Santos Miranda.

Por último agradeço à Escola Politécnica da Universidade São Paulo pela oportunidade de dar continuidade aos meus estudos, e à CAPES pelo auxílio financeiro. 
Uma coisa que se revela nos mitos é que, no fundo do abismo, desponta a voz da salvação. O momento crucial é aquele em que a verdadeira mensagem de transformação está prestes a surgir. No momento mais sombrio surge a luz.

(...) O labirinto é conhecido em toda a sua extensão. Temos apenas de seguir a trilha do herói, e lá, onde temíamos encontrar algo abominável, encontraremos um deus. E lá, onde esperávamos matar alguém, mataremos a nós mesmos. Onde imaginávamos viajar para longe, iremos ter ao centro de nossa própria existência. E lá, onde pensávamos estar sós, estaremos na companhia do mundo todo.

Joseph Campbell 


\section{Resumo}

Sincronismo é um comportamento dinâmico que pode ser detectado na atividade dos neurônios que formam estruturas corticais, e essa atividade parece ser fundamental para a realização de processos relacionados a aprendizado, compreensão e reconhecimento. Estruturas corticais podem ser modeladas por redes de mapas acoplados. Nessas redes, a existência de solução síncrona é determinada pela equação que governa a atividade de cada mapa, pela topologia de acoplamento entre os mapas e pelos valores dos parâmetros. O enfoque deste trabalho é empregar redes de mapas acoplados voltados à detecção de simetria, e segmentação de imagens, via sincronismo. 


\begin{abstract}
Synchronism is a dynamical behavior that can be found in the neural activity of cortical structures, and this behavior seems to be fundamental in learning, understanding and recognition processes. Cortical structures can be modeled by using coupled map lattices. In such lattices, the existence of synchronous solution is determined by the equation that rules the activity of each map, by the coupling topology among the maps, and by the parameter values. The goal of this work is to employ coupled map lattices in symmetry detection and image segmentation, via synchronism.
\end{abstract}




\section{SUMÁRIO}

\section{MOTIVAÇÃO E INTRODUÇÃO}

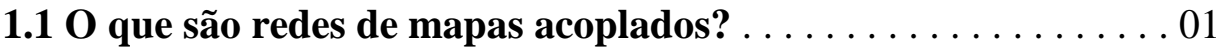

1.2 Vantagens do uso de mapas acoplados em processamento de

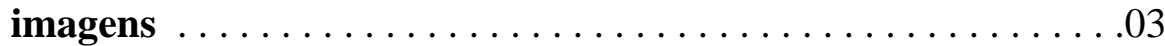

1.3 Propostas deste trabalho $\ldots \ldots \ldots \ldots \ldots \ldots \ldots \ldots \ldots \ldots . \ldots . \ldots \ldots$

\section{CONCEITOS FUNDAMENTAIS}

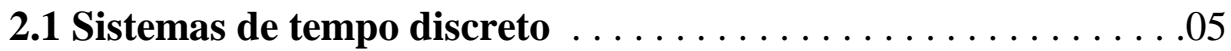

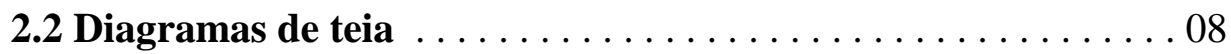

2.3 Bifurcações e caos em sistemas de tempo discreto . . . . . . . 09

2.4 Redes de mapas acoplados $\ldots \ldots \ldots \ldots \ldots \ldots \ldots \ldots \ldots$

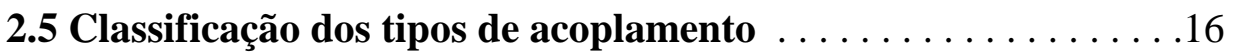

2.6 Postulado de Hebb e auto-organização em mapas acoplados . . 20

2.7 Analogia entre o neurônio artificial e o modelo logístico … . . 22

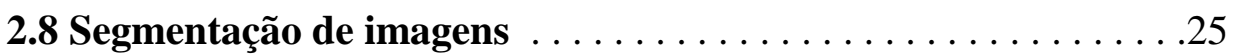

3. MAPAS ACOPLADOS: DETECÇÃO DE SIMETRIA

3.1 Comentários sobre trabalhos anteriores $\ldots \ldots \ldots \ldots \ldots 31$

3.2 Modelo desenvolvido: heurísticas e resultados . . . . . . . . 34

4. MAPAS ACOPLADOS: SEGMENTAÇÃO DE IMAGENS

4.1 Conceitos preliminares $\ldots \ldots \ldots \ldots \ldots \ldots \ldots \ldots \ldots 4$

4.2 Modelo desenvolvido: heurísticas e resultados $\ldots \ldots \ldots .58$

5. CONSIDERAÇÕES FINAIS $\ldots \ldots \ldots \ldots \ldots \ldots \ldots \ldots \ldots$ 


\section{MOTIVAÇÃO E INTRODUÇÃO}

\subsection{O que são redes de mapas acoplados?}

$\mathrm{O}$ estudo de redes de mapas acoplados (coupled map lattice - CML) foi introduzido por Kunihiko Kaneko, em 1983, como um modelo a parâmetros distribuídos para a análise da formação de padrões espaciais em sistemas dinâmicos. Em sua tese de doutorado, republicada posteriormente em forma de livro [Kaneko, 1986], ele investigou caos espaço-temporal em tais tipos de redes. Nas últimas duas décadas, os mapas acoplados têm sido usados para modelar os mais diversos sistemas, sejam eles: físicos, econômicos ou biológicos [Kaneko, 1993]. Geralmente, sistemas com muitos elementos acoplados (com interdependência) podem evoluir de forma complexa, o que impossibilita que sua dinâmica seja determinada por métodos analíticos. Utilizam-se mapas acoplados como uma forma de modelar sistemas complexos com muitos elementos interagindo entre si, pois a solução numérica é facilmente obtida.

Um mapa acoplado, ou CML, é um sistema dinâmico cujas variáveis referentes ao tempo e ao espaço assumem valores discretos, porém seus estados assumem valores contínuos [Kaneko, 1993]. Ele pode servir como aproximação numérica de um sistema dinâmico acoplado descrito por equações a derivadas parciais. Num sistema dinâmico de equações a derivadas parciais (PDE - partial differencial equations), espaço, tempo e estado assumem valores contínuos, daí a impossibilidade de uma simulação computacional deste tipo de sistema usando de computadores digitais, sendo necessário um hardware analógico dedicado [Hernandez et al, 2003]. Usualmente, para sistemas dinâmicos acoplados invariantes (isto é, cujas leis que definem a sua dinâmica não se alteram com o espaço), faz-se uso de mapas acoplados, ou mesmo de autômatos celulares (CA - celular automata). Estes foram introduzidos por Ulam e von Neumann [Kaneko, 1993]; sendo considerados os extremos da discretização, já que até os estados assumem 
valores discretos finitos. Um exemplo clássico de autômato celular é o Game of Life de Conway.

\begin{tabular}{cccc}
\hline Modelo & Espaço & Tempo & Estado \\
\hline CA & D & D & D \\
CML & D & D & C \\
PDE & C & C & C \\
\hline
\end{tabular}

Tabela 1.1 - Classificação dos sistemas acoplados, sendo D = discreto e C = contínuo. Extraído de [Kaneko, 1993]

Redes de mapas acoplados têm sido usadas como modelos de vários sistemas, como, por exemplo, estruturas corticais. Sincronismo é um comportamento dinâmico que pode ser detectado na atividade dos neurônios que formam nosso córtex, e essa atividade parece ser fundamental para a realização de processos relacionados a aprendizado, associação cognitiva e reconhecimento de padrões [DeMaris, 2002; Sánchez, et al, 2004]. Num modelo de mapas acoplados, a existência ou não de solução síncrona é determinada pela equação que governa a atividade de cada mapa, pela topologia de acoplamento entre os mapas e pelos valores numéricos dos parâmetros. Sincronismo pode ser usado numa rede de mapas acoplados para processamento de imagens, como discutido a seguir. De acordo com Kaneko [1986], alguns dos objetivos das pesquisas em mapas acoplados são:

i) estudar um sistema com grande número de modos excitados;

ii) caracterização de padrões espaciais;

iii) construção de modelos de mecânica estatística para sistemas com complexidade espaço-temporal;

iv) estudar o intervalo e o desenvolvimento do caos quando um parâmetro de bifurcação é alterado;

v) modelamento de sistemas com bifurcação espacial. 


\subsection{Vantagens do uso de mapas acoplados em processamento de imagens}

O uso de mapas acoplados pode oferecer vantagens em relação às técnicas usuais de processamento e pré-processamento de imagens; já que possui algumas das características do cérebro que aumentam a velocidade e a robustez do processamento, tais como paralelismo e múltiplas conexões. Mimetizar circuitos neurais traz tanto a possibilidade de melhorar a arquitetura e a organização dos hardwares atuais quanto melhorar a compreensão funcional do próprio cérebro biológico. Um exemplo de implementação de hardware dedicado a mapas acoplados pode ser encontrado em Hernandez et al [2003].

Além disso, mapas acoplados oferecem a possibilidade de funcionamento assíncrono. Devido ao fato de o processamento não precisar ser necessariamente seqüencial não há necessidade de ciclos de controle. Nas situações em que o sincronismo é necessário, ele é criado pela iteração dos próprios elementos da rede.

$\mathrm{Na}$ nomenclatura do estudo de mapas acoplados, diz-se que quando diversos elementos interconectados por acoplamento entram em sincronia, formam um cluster e que todos os elementos pertencentes a um mesmo cluster estão num estado dito coerente.

\subsection{Propostas deste trabalho}

O propósito deste trabalho é investigar a possibilidade de utilização de sistemas compostos por mapas acoplados no processamento de imagens. Inicialmente, levantamos a seguinte questão: como extrair informação de uma imagem? A análise de uma informação é um processo que a subdivide em suas partes constituintes. Dessa forma, fica mais simples examinar cada parte da informação separadamente em vez do conjunto todo. É por causa disso que, 
geralmente, a segmentação é o primeiro passo em análise de imagens. A segmentação é um pré-processamento que subdivide uma imagem em suas partes ou objetos constituintes.

Nosso principal objetivo é estudar formas de realizar processamento de imagens fazendo uso de mapas acoplados. Para segmentação, a idéia é controlar a formação de clusters, de modo a relacionar cada uma das figuras constituintes de uma imagem a um cluster. Deseja-se, assim, que todos os elementos de uma figura entrem em sincronia, separando as partes, de modo que cada uma exiba um sincronismo diferente das outras. A forma com que isso é feito é explicada no capítulo 4. Outra informação que pode ser extraída de uma imagem é se ela é ou não simétrica. No capítulo 3, apresenta-se um método para detecção de simetria via sincronismo de mapas.

O próximo capítulo aborda conceitos introdutórios de mapas. 


\section{CONCEITOS FUNDAMENTAIS}

\subsection{Sistemas de tempo discreto}

Sistemas dinâmicos de tempo discreto são aqueles em que as mudanças ocorrem apenas em determinados instantes de tempo. O tempo é a variável independente e os possíveis valores de tempo formam um conjunto enumerável. Sistemas de tempo discreto são, muitas vezes, aproximações para sistemas de tempo contínuo. Por exemplo, uma entrada de tempo contínuo pode ser amostrada de forma periódica, de modo a ser transformada em um sinal de tempo discreto. Para um sistema de tempo contínuo ser simulado computacionalmente, o tempo deve necessariamente ser discretizado, pois o computador é uma máquina que funciona sob lógica seqüencial de tempo discreto. Vários sistemas são convenientemente representados em termos de equações de tempo discreto, o que não significa que essas grandezas só possam existir ou serem determinadas de tempos em tempos. Um exemplo clássico é uma aplicação financeira cujos rendimentos são creditados somente uma vez por mês [Monteiro, 2006].

Sistemas dinâmicos de tempo contínuo costumam ser regidos por equações diferenciais. E a diferencial nada mais é do que uma diferença de valores infinitesimalmente espaçados de uma variável independente que tende a zero. É através da transformação de equações diferenciais em equações de diferenças que um sistema de tempo contínuo passa a ser representado por um sistema de tempo discreto. A transformação é conveniente, pois geralmente é mais fácil solucionar numericamente sistemas de tempo discreto do que sistemas de tempo contínuo. De fato, sistemas de tempo discreto podem ser 
solucionados de forma recursiva, já que as equações de diferenças são, na verdade, equações de recorrência.

Por exemplo, a equação diferencial de Verhulst modela uma dinâmica de crescimento populacional. Em contraposição ao modelo linear de Malthus, que previa uma evolução temporal exponencial de aumento da população, o modelo de Verhulst apresenta saturação, pois esse modelo prevê a estagnação do crescimento populacional devido à limitação de recursos. A equação de tempo contínuo do modelo de Verhulst é:

$$
\frac{d N}{d t}=r \cdot N \cdot\left(1-\frac{N}{k}\right)
$$

sendo o tempo $t$ a variável independente; $N$ a variável dependente que representa a concentração populacional; $k$ um parâmetro positivo que representa a limitação do crescimento; e $r$ um parâmetro positivo que representa crescimento exponencial no limite $N \rightarrow 0^{+}$. Vale ressaltar que a concentração populacional $N$ é uma variável contínua, apesar de uma população ser, na realidade, enumerável, i.e., quantificada por um número inteiro. A aproximação contínua é necessária para descrever um sistema por meio de equações diferenciais.

Obtém-se assim a seguinte equação de diferença como versão de tempo discreto do modelo de Verhulst:

$$
\frac{\Delta N}{\Delta t}=\frac{N(t+\Delta t)-N(t)}{\Delta t}=r \cdot N(t) \cdot\left(1-\frac{N(t)}{k}\right)
$$

donde se obtém: 


$$
N(t+\Delta t)=(r \cdot \Delta t+1) \cdot N(t)-(r \cdot \Delta t / k) \cdot N^{2}(t)
$$

A equação de diferença (2.3) pode ser simplificada, tomando a normalização da unidade de tempo $\Delta t=1$, e por uma mudança de variável. Como a nova variável $x(t)$ que deve substituir $N(t)$ também expressa uma medida de concentração populacional, ela deve ser proporcional a $N(t)$, e pode ser escrita na forma $N(t)=\varphi \cdot x(t)$, sendo $\varphi$ uma constante a ser convenientemente escolhida de modo a simplificar a equação (2.3). Substituindo essa relação na equação (2.3), obtém-se:

$$
\varphi \cdot x(t+1)=(r+1) \cdot \varphi \cdot x(t)-(r / k) \cdot \varphi^{2} \cdot x^{2}(t) .
$$

Como a constante de transformação de escala $\varphi$ é arbitrária, um valor conveniente que simplifique a equação (2.3) pode ser escolhido. Pode-se então determinar o valor de $\varphi$ que permite uma fatoração igualando os coeficientes $(r+1) \cdot \varphi=(r / k) \cdot \varphi^{2}$ obtendo $\varphi=k \cdot(r+1) / r$, o que possibilita escrever a equação (2.3) na seguinte forma fatorada:

$$
x(t+1)=\mu \cdot x(t) \cdot(1-x(t))
$$

sendo $\mu=r+1$ um novo parâmetro. A representação discreta feita na equação (2.4) apresenta um menor custo computacional do que a equação (2.3), o que simplifica a resolução numérica. A palavra mapa é usualmente utilizada como sinônimo de equação de diferenças, como processo iterativo de tempo discreto [Strogatz, 1994]. E a versão discreta da equação (2.4) da equação de Verhulst é mais conhecida pelo nome de mapa logístico, e é extremamente importante no estudo de bifurcações e caos em sistemas de tempo discreto. O parâmetro $\mu$, por sua vez, determina o aspecto qualitativo do regime permanente, sendo mais conhecido pelo nome de parâmetro de bifurcação. 


\subsection{Diagramas de teia}

Conhecendo-se o estado inicial, todos os estados seguintes de um mapa podem ser obtidos por recorrência. O gráfico do diagrama de teia serve para visualizar as sucessivas iterações de um mapa. Para o mapa logístico $f_{\mu}(x(t))=\mu \cdot x(t) \cdot(1-x(t))$, com $f_{\mu}(x(t))=x(t+1)$ é possível notar que a relação de recorrência dada pela função $f_{\mu}(x(t))$ é uma parábola. Então, dado um valor inicial $x(t)$ é possível encontrar $x(t+1)$ graficamente com uma reta vertical partindo de $x(t)$ até a parábola $f_{\mu}(x(t))$. Para encontrar $x(t+2)$ graficamente pode-se partir do valor obtido para $x(t+1)$ no eixo $x(t)$. Porém, em vez disso, pode-se traçar uma continuação horizontal do ponto $x(t+1)$ anteriormente encontrado na curva até a bissetriz $x(t+1)=x(t)$. Esse procedimento pode ser repetido indefinidamente para obter a evolução de tempo discreto, como ilustrado na figura (2.1).

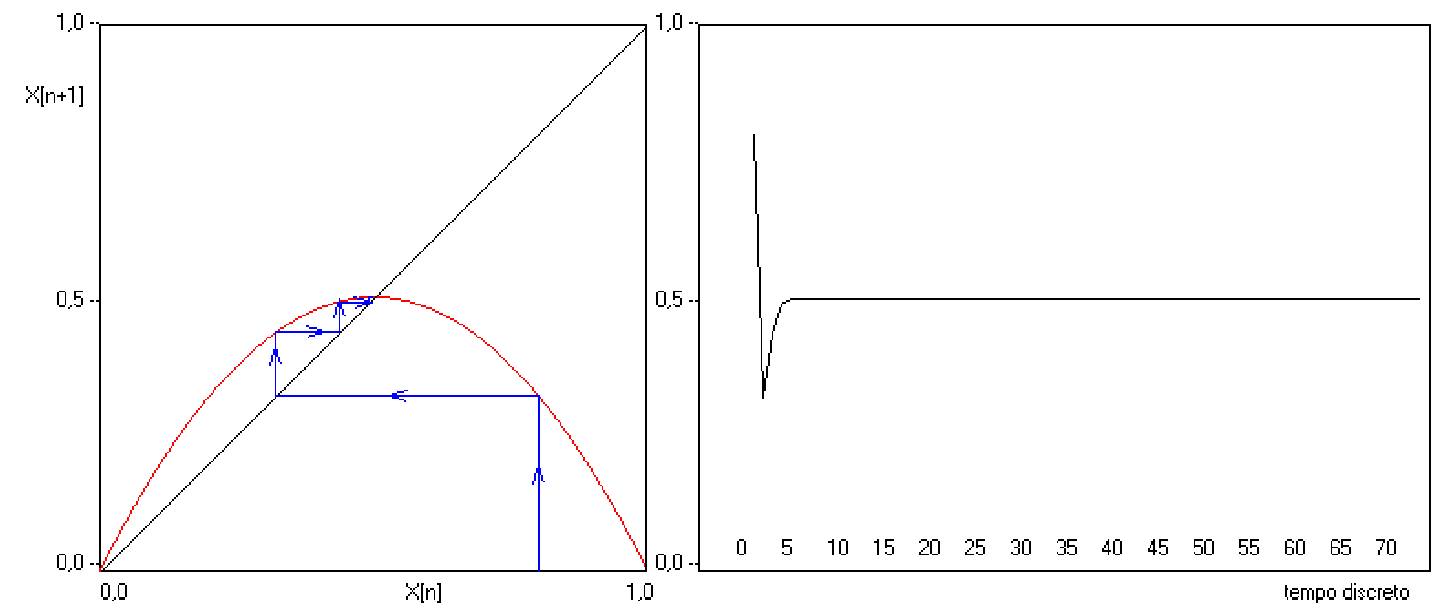

Figura 2.1. - À esquerda o diagrama de teia para $\mu=2$ partindo do valor inicial $x(0)=0,8$ e à direita a resposta temporal.

É importante ressaltar que o método do diagrama de teia é aplicável para qualquer mapa, e não apenas ao mapa logístico. 


\subsection{Bifurcações e caos em sistemas de tempo discreto}

A função logística $f_{\mu}(x)=\mu \cdot x \cdot(1-x)$ apresenta um parâmetro $\mu$ que determina a forma da parábola no diagrama de teia, e, conseqüentemente, a dinâmica do mapa logístico. Alterações no valor de $\mu$ podem provocar alterações qualitativas na dinâmica do mapa no regime permanente. Os valores de $\mu$ em que a mudança qualitativa da resposta ocorre são chamados de bifurcações, e $\mu$ é comumente chamado de parâmetro de bifurcação. A codimensão um mapa é o número de parâmetros de bifurcação que ele possui. Portanto, o mapa logístico possui codimensão igual a 1.

Cada ponto que se repete com periodicidade na resposta dinâmica é denominado de ponto fixo. $O$ parâmetro de bifurcação $\mu$ é associado ao comportamento dinâmico no regime permanente, determinando o número de pontos fixos que o mapa vai apresentar em sua órbita periódica. Por uma órbita de período $T$ define-se:

$$
\exists T \in \mathfrak{\aleph}: x(t+T)=x(t)
$$

Por exemplo, para $\mu=3,4$ a resposta apresenta órbita de período 2 no regime permanente como pode ser visto na figura (2.2), enquanto para $\mu=2$ há um único ponto fixo conforme mostrado na figura (2.1). 


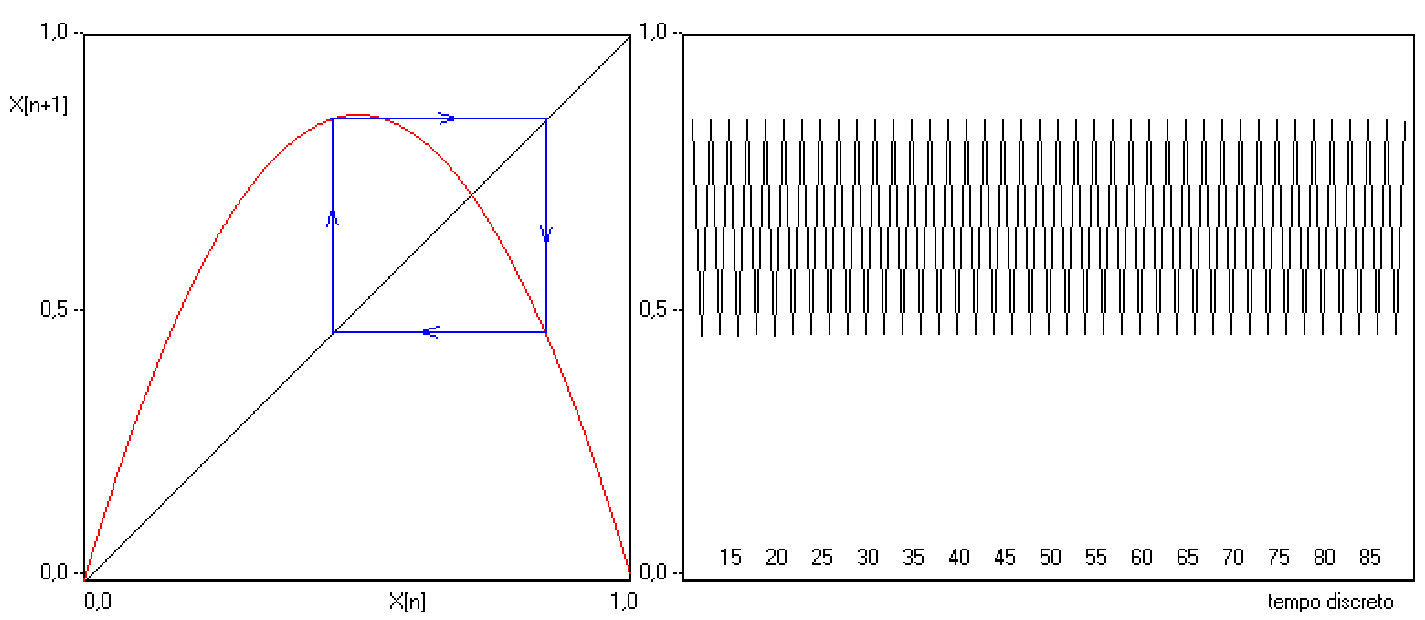

Figura 2.2 - Diagrama de teia e evolução temporal do mapa logístico no regime permanente para $\mu=3,4$.

Como o número de pontos que formam a órbita do atrator duplicou, existe uma bifurcação entre $\mu=2$ e 3,4. De fato, ela ocorre em $\mu=3$. E, como houve uma duplicação de período, diz-se que ocorreu uma bifurcação do tipo flip.

Quanto mais próximo o valor do parâmetro $\mu$ está de uma bifurcação, maior a duração do transiente. Por exemplo, para $\mu=3$ a resposta tende a mostrar características híbridas de um ponto fixo e de órbita de período 2 simultaneamente. A bifurcação flip é estruturalmente estável em regiões nãocaóticas para perturbações pequenas na dinâmica [Friedler-Ferrara e Prado, 1994]. Faz algum sentido afirmar isso, já que o expoente de Lyapunov (que caracteriza a natureza caótica de um sistema) é negativo na vizinhança desse tipo de bifurcação para o mapa logístico; o que significa que a diferença entre duas trajetórias inicialmente muito próximas tende a decair exponencialmente com o tempo. Como pode ser visto na figura (2.3), a resposta tende aparentemente a formar uma órbita de período 2, mas cuja distância entre os dois pontos vai lentamente decaindo. 


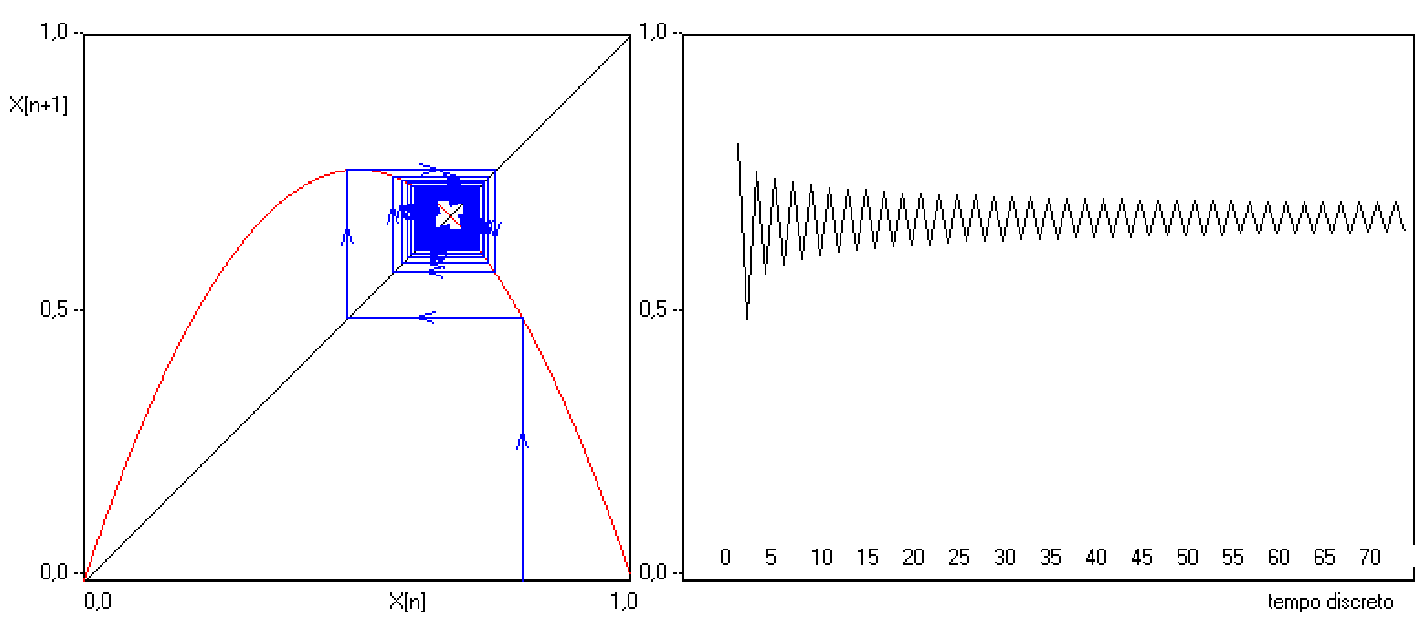

Figura 2.3 - Diagrama de teia e evolução temporal próximo de $\mu=3$, uma bifurcação do tipo flip.

O diagrama de teia ajuda a visualização da dinâmica do mapa para um único valor do parâmetro de bifurcação $\mu$. Entretanto, ele não oferece uma indicação global de todos os pontos de bifurcação e órbitas periódicas de uma única vez. Esta visualização é feita no diagrama de bifurcação.

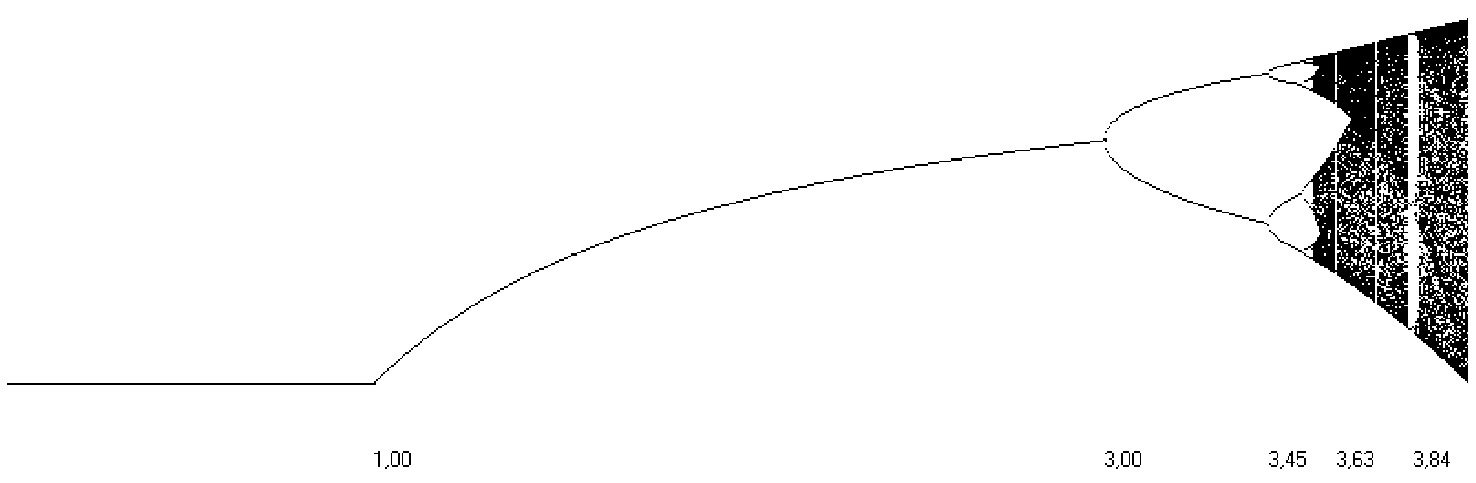

Figura 2.4 - Diagrama de bifurcação do mapa logístico.

Diagramas de bifurcação de mapas, como o da figura (2.4), mostram a variação do parâmetro de bifurcação na abscissa e suas respectivas órbitas periódicas na ordenada. Através de diagramas de bifurcação, as órbitas do regime permanente podem ser relacionadas com o valor do parâmetro $\mu$. 
Quanto maior o valor desse parâmetro, mais rapidamente as bifurcações flip vão surgindo. À medida que $\mu$ se aproxima de um limiar em torno de 3,56 o número de bifurcações flip cresce tão rapidamente que tende ao infinito. A partir desse valor, tem-se a região caótica. Entretanto, não existe apenas caos para $\mu>3,56$. Na verdade, existem infinitas janelas com órbitas de período finito. Pode-se dizer que a região do parâmetro de bifurcação em que $3,56<\mu \leq 4$ possui uma alternância incomensurável de caos e ordem, porque o intervalo caótico contém infinitas janelas de períodos finitos, entremeadas por intervalos caóticos [Fiedler-Ferrara e Prado, 1994].

A figura (2.5) mostra algumas janelas periódicas. Essa figura detalha mais a região caótica da figura (2.4), permitindo a visualização de novas janelas. Quanto mais se detalha na região caótica, mais janelas periódicas vão aparecendo. Na figura (2.6) pode-se observar o diagrama de teia correspondente ao comportamento dinâmico numa janela de período 3.

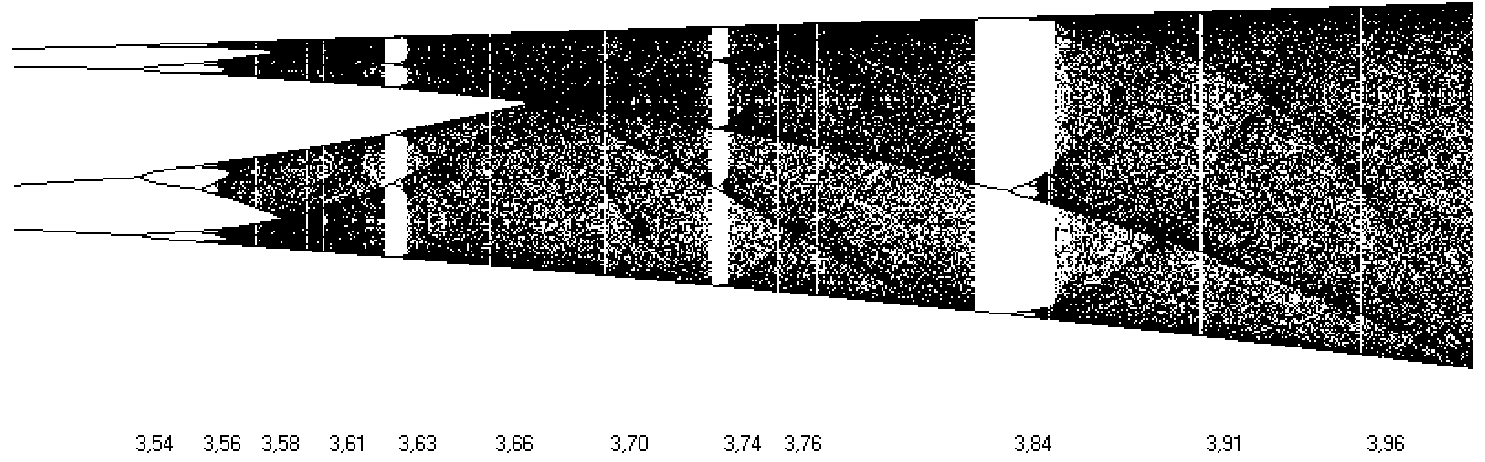

Figura 2.5 - Detalhe na região caótica do diagrama de bifurcação do mapa logístico. 


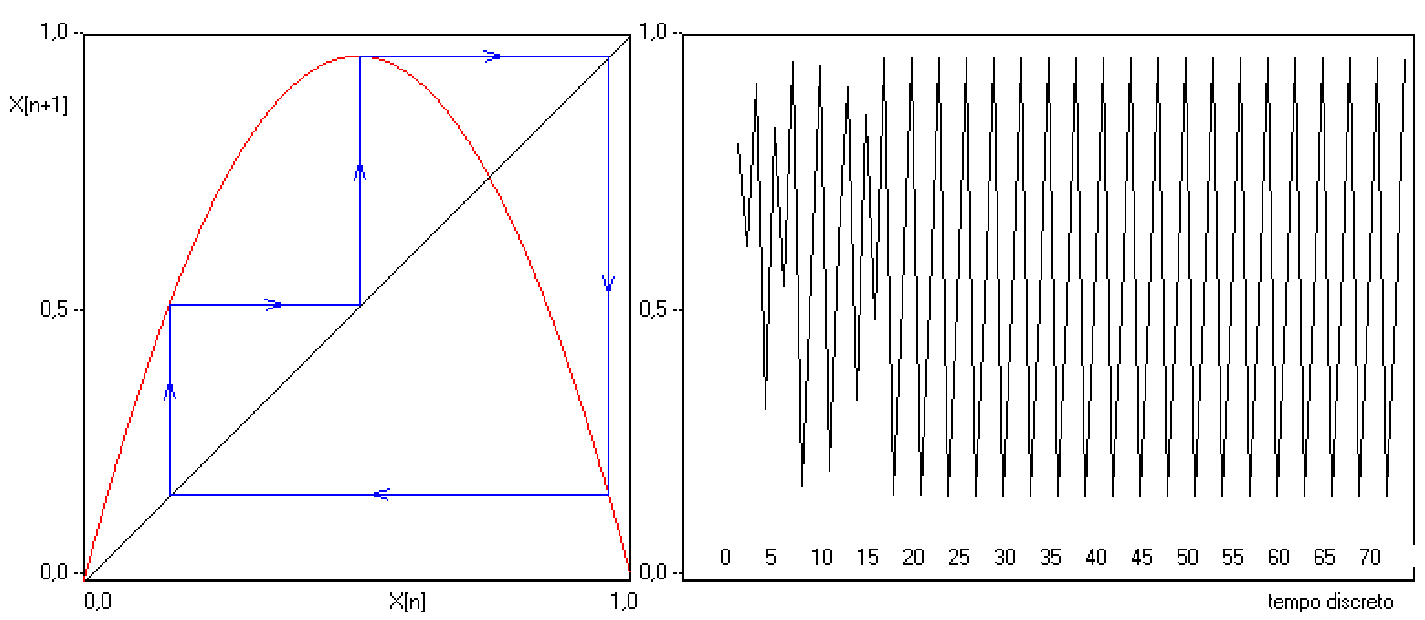

Figura 2.6 - Diagrama de teia estacionário e comportamento dinâmico do regime transiente ao estacionário em uma janela de período 3 , com $\mu=3,83$.

\subsection{Redes de mapas acoplados}

Redes são basicamente agrupamentos de vários sistemas elementares formando um conjunto mais complexo e oferecendo maior gama de possibilidades de comportamento que o elemento isolado. Redes de moléculas são fundamentais para os processos fisiológicos dos seres vivos. Isso significa que o conceito de redes é bem mais genérico do que o usual, podendo ser aplicado não só ao estudo da engenharia e da computação, mas também como modelo dos mais diversos sistemas, tais como, redes de neurônios, contatos sociais, ou até especulações financeiras na bolsa de valores [Oliveira, 2004].

A dinâmica das redes de osciladores acoplados é determinada pela forma das equações que governam cada oscilador, pela maneira através da qual se dá o acoplamento, pela distribuição das frequiências naturais dos osciladores, pelos atrasos envolvidos na propagação do sinal de um oscilador para outro, pela presença ou não de ruído. O limiar da sincronização corresponde a um 
ponto de bifurcação: por exemplo, pode acontecer que, quando o valor do parâmetro que caracteriza o acoplamento entre os osciladores excede um número crítico, o sistema passe de um estado incoerente para um estado sincronizado, em que os osciladores apresentam espectro de frequiência único e relações de fases fixas [Monteiro, 2005]. É com base nesses conceitos de interação e dinâmica não-linear que nasce a idéia de mapas acoplados aplicados ao modelamento de sistemas complexos.

Por acoplamento, subentende-se uma interdependência entre os comportamentos dos seus elementos (mapas) constituintes. Mesmo que um mapa apenas se comunique com alguns dos seus vizinhos de forma direta, comunica-se com todos os outros mapas de forma indireta, se todos interagirem com seus respectivos vizinhos. Pode-se, então, dizer que a dinâmica de mapas acoplados é de natureza holística, pois a influência do estado de cada mapa é partilhada por todos os outros.

A presença de um acoplamento entre elementos indica que não há como simplificar o estudo desse sistema analisando-os de forma isolada dos demais. Se a cada elemento for atribuído um valor escalar para especificar seu estado, o estado futuro de cada mapa dependerá do estado atual de todos aqueles que fazem parte do acoplamento. $\mathrm{O}$ estado de um sistema dinâmico é constituído pelo menor número possível de variáveis que determina completamente a sua evolução. $\mathrm{O}$ conhecimento do estado num tempo $t=t_{0}$ implica $\mathrm{o}$ conhecimento do seu estado em qualquer tempo futuro $t>t_{0}$ [Ogata, 2003]. Se há $N$ elementos acoplados entre si, então existem $N$ equações acopladas, não havendo a possibilidade de eliminar qualquer uma por meio de substituição ou mudança de variável. Pode-se dizer que existe um sistema com $N$ dimensões e que não há como reduzir o número de dimensões do estado sem perder informação para prever sua dinâmica. Em um sistema acoplado, todos os elementos contribuem para a evolução do sistema. 
Um exemplo de acoplamento entre dois mapas segue abaixo:

$$
\begin{aligned}
& x(t+1)=(1-\varepsilon) \cdot f_{\mu}(x(t))+\varepsilon \cdot f_{\mu}(y(t)) \\
& y(t+1)=(1-\varepsilon) \cdot f_{\mu}(y(t))+\varepsilon \cdot f_{\mu}(x(t))
\end{aligned}
$$

sendo que $f_{\mu}(x)=\mu \cdot x \cdot(1-x)$ é a função logística do mapa com parâmetro de bifurcação $\mu$ e constante de acoplamento $\varepsilon$. Vale ressaltar que esse é um acoplamento simétrico, pois trocando as variáveis $x$ e $y$ o sistema permanece inalterado.

Para $\mu=3,8$, um valor em que o mapa logístico apresenta dinâmica caótica, conforme é possível constatar na figura (2.5), e $\varepsilon=0,2$ tem-se uma resposta no domínio do tempo exibindo um comportamento peculiar, como mostrado na figura (2.7). É possível observar a existência de batimentos irregulares, sendo que a dinâmica permanece caótica, de modo que não é possível estabelecer uma fórmula analítica capaz de prever o valor exato do estado de cada mapa após longo prazo. Mas é possível notar certa "periodicidade" que pode levar a uma especulação de como padrões aproximadamente periódicos, como os das ondas cerebrais ou batimentos cardíacos, podem ser formados através de acoplamento de sistemas com dinâmica caótica. 

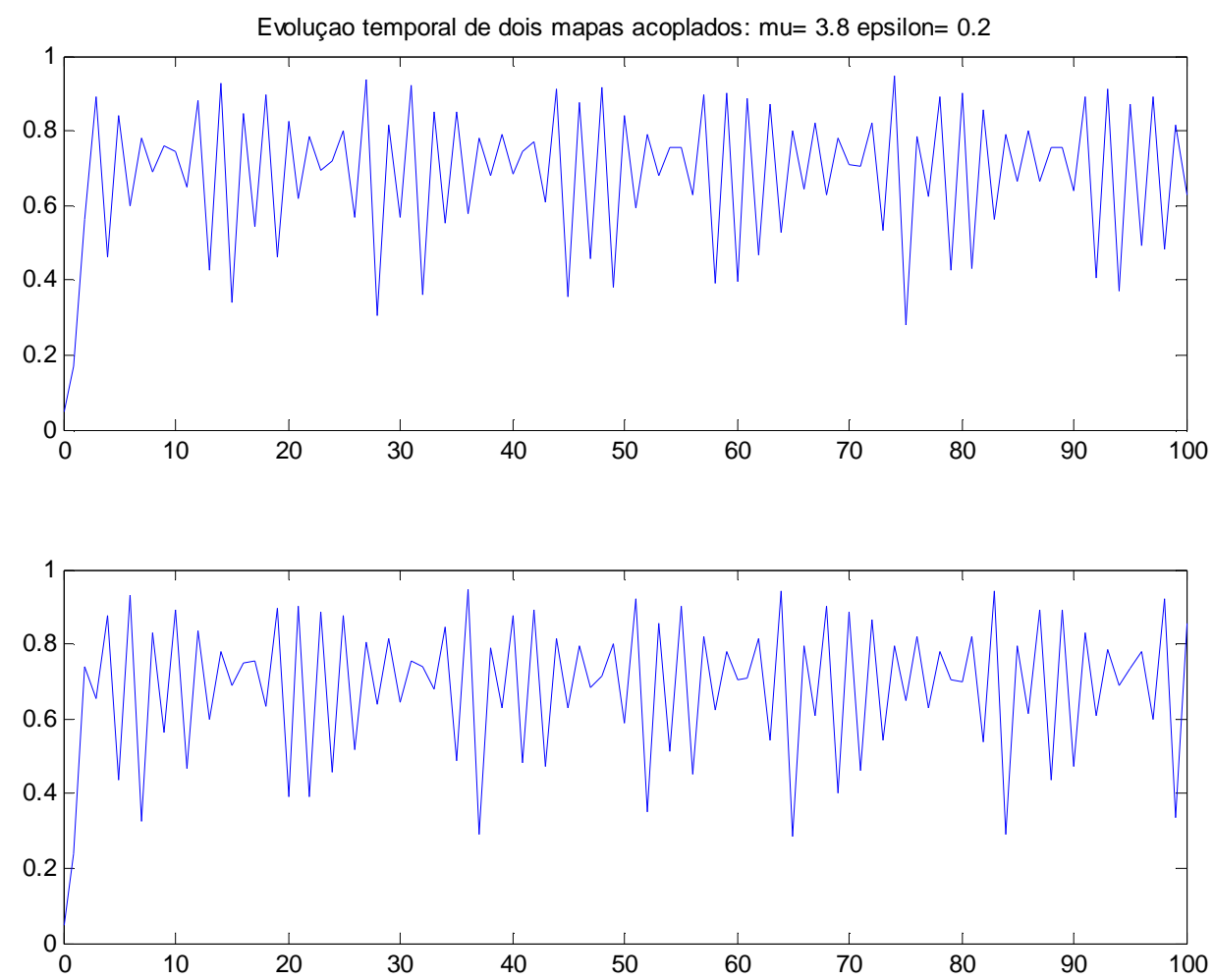

Figura 2.7 - Um exemplo de comportamento de dois mapas acoplados com dinâmica caótica.

\subsection{Classificação dos tipos de acoplamento}

O acoplamento entre mapas pode ser classificado quanto à direção como:

- Unidirecional: Também chamado de acoplamento mestre-escravo. A evolução do sistema mestre não se altera pela evolução do sistema do escravo. Esse por sua vez tem sua evolução determinada como uma função dos estados de ambos. Em essência, pode-se dizer que o mestre encontra-se desacoplado (independente), enquanto o escravo está acoplado ao mestre. 
- Bidirecional: Quando a influência de um sistema sobre o outro é mútua e os mapas interagem entre si. Porém, apesar de mútua, a influência não precisa ser necessariamente a mesma, de modo que $o$ acoplamento num sentido pode ser maior do que no outro. Quando a influência é idêntica o acoplamento é dito simétrico.

Quanto à conectividade, o acoplamento pode ser classificado como:

- Regular: A relação de conectividade válida para um mapa é também válida para todos os outros. Ou seja, existe uma regra de conectividade que se aplica em todos os mapas da rede. Por exemplo, se um mapa se conecta só com o da esquerda com um acoplamento $\varepsilon$ e com o da direita com um acoplamento $\alpha$, então essa regra se aplica a todos os outros mapas da mesma maneira.

- Irregular: Quando não existe um padrão quanto às regras de acoplamento.

- Global: É um acoplamento regular em que cada mapa interage com todos os outros elementos da rede da mesma forma. Mapas parametrizados e globalmente acoplados são comumente descritos pelo seguinte sistema de equações:

$$
x_{i}(t+1)=(1-\varepsilon) \cdot f_{\mu}\left(x_{i}(t)\right)+\frac{\varepsilon}{N} \cdot \sum_{j=1}^{N} f_{\mu}\left(x_{j}(t)\right)
$$

em que $x_{i}(t)$ representa o valor do $i$-ésimo elemento em função do tempo; o somatório representa o acoplamento global; $f_{\mu}(x)=\mu \cdot x \cdot(1-x)$ é a função do mapa logístico com o parâmetro de bifurcação $\mu$; o termo $\varepsilon$ é a constante de acoplamento global e $N$ é o número total de mapas. Mapas com acoplamento global tendem a se sincronizar mais rapidamente [Oliveira e Monteiro, 2002], o que é intuitivo, já que esse apresenta uma difusão maior que o acoplamento local, o que tende a levar todos os mapas a se aproximarem de um 
valor médio. É natural que para valores de $\varepsilon$ muito próximos de 1 exista uma forte tendência de sincronização num estado coerente, em que todos os mapas estão simultaneamente num mesmo estado. Com acoplamento unitário, a sincronização em um estado coerente é instantânea, ocorrendo já na primeira iteração. Isso pode nos levar a especular sobre um possível limiar de acoplamento global a partir do qual o mapa acoplado converge para o estado coerente num tempo finito.

- Local: É um tipo de acoplamento em que cada mapa se conecta só com os elementos vizinhos. O acoplamento local é geralmente regular, mas também pode ser irregular com o intuito de obter respostas com determinadas características espaciais.

- Dimensão da rede: Mapas acoplados em uma ou duas dimensões (ao longo de uma reta ou um plano, respectivamente) costumam ser os mais vistos na literatura. Exemplos de acoplamentos locais regulares bidimensionais de mapas são os de vizinhança de von Neumann, em que a conectividade de um mapa se dá apenas com os vizinhos da horizontal e vertical, apresentando uma conectividade-de-4 e a vizinhança de Moore que inclui também os elementos diagonais. A vizinhança de Moore pode ser de raio 1, apresentando uma conectividade-de-8 de raio 2, com uma conectividade-de-24 e assim por diante. Esses tipos de acoplamentos são mostrados na figura (2.8).

- Dimensão dinâmica dos mapas: Os mapas individualmente não precisam ser de primeira ordem, como o logístico, podendo possuir ordem maior. 


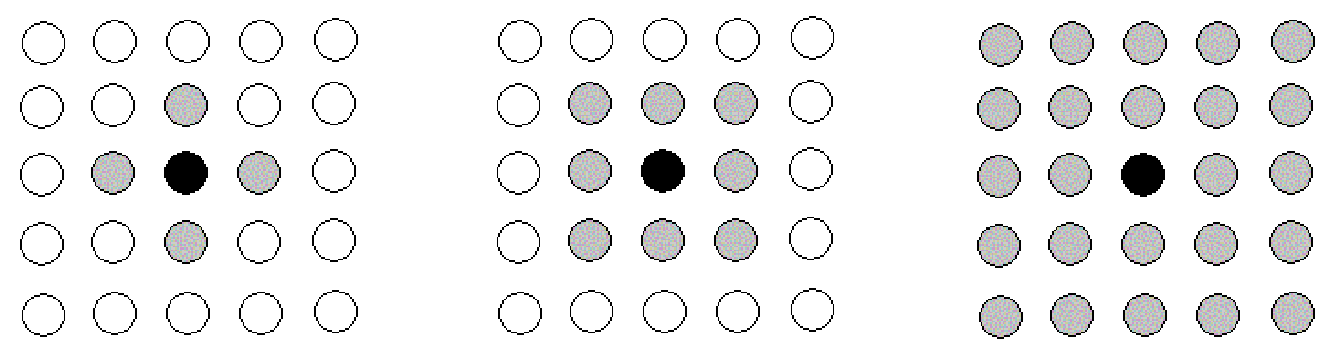

Figura 2.8 - Diagramas representando diferentes formas de acoplamento bidimensional. A figura da esquerda representa uma vizinhança de von Neumann; a central representa uma vizinhança de Moore de raio 1; e a da esquerda uma vizinhança de Moore de raio 2.

Geralmente, estudam-se redes unidimensionais ou bidimensionais de mapas. No caso de processamento de imagens planas, a rede é naturalmente bidimensional. Na figura (2.9), há uma representação em níveis de cinza de uma rede bidimensional com acoplamento regular misto de global e local (usando uma vizinhança de Von Neumann de raio 1) com mapas interagindo sob dinâmica caótica e valores iniciais aleatórios.

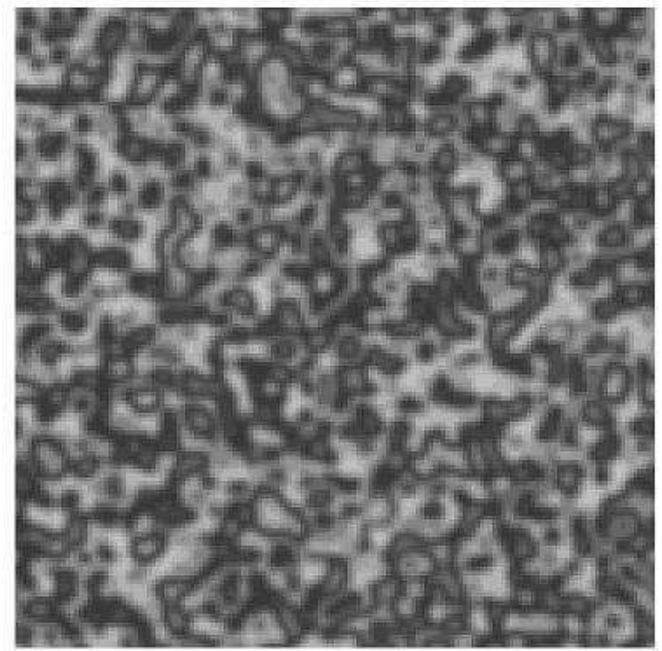

Figura 2.9 - Mapa acoplado bidimensional, inicializado com valores aleatórios com acoplamento global de 0,1 e local de 0,8; regido pela dinâmica do mapa logístico com parâmetro de bifurcação 3,8 após 50 iterações. 


\subsection{Postulado de Hebb e auto-organização em mapas acoplados}

O postulado de Hebb do aprendizado, ou simplesmente lei de Hebb, pode ser induzido do princípio de que o aprendizado se desenvolve a partir de relações de associação, isto é, que a construção do conhecimento é um processo de natureza associativa. Uma forma de representar a lei de Hebb é fornecida a seguir [Haykin, 1994]:

1- Se dois neurônios ligados por uma sinapse (conexão) são ativados simultaneamente (i.e. em sincronia), então a intensidade dessa sinapse é incrementada.

2 - Se dois neurônios ligados por uma sinapse são ativados fora de sincronia, então a intensidade desta sinapse tende a enfraquecer, sendo decrementada.

A lei de Hebb pode ser vista tanto como um princípio associativo, quanto como um princípio que visa um condicionamento da rede. A clássica experiência do cão de Pavlov é uma evidência de que o cérebro animal tende a ter seu comportamento condicionado. Mesmo que seja pela associação entre estímulos que não tenham necessariamente uma relação de significado, como é o caso da campainha e do alimento. Foi uma heurística adotada pelos organismos vivos durante o processo de seleção natural como tentativa de reforçar relações entre causa e efeito, possibilitando certa capacidade de realizar inferências que aumentaram as chances de sobrevivência.

Um sistema é auto-organizante se ele adquire, espontaneamente, uma estrutura de natureza funcional, temporal e/ou espacial, demonstrada pelo surgimento de uma coerência de longo alcance entre as variáveis do sistema. Esse processo ocorre de maneira espontânea quando um determinado parâmetro cruza um valor crítico; isso permite que uma flutuação aleatória 
interna seja amplificada, disparando o processo auto-organizante. Von Foerster chamou esse processo de "ordem a partir do ruído"; Prigogine chamou-o de "ordem a partir das flutuações" [Monteiro, 2005]. O princípio da autoorganização estabelece que a ordem global pode surgir de iterações locais; ou seja, o padrão global de um sistema (nível macroscópico) surge unicamente pelas iterações locais (nível microscópico) [Sansão, 2003; Oliveira, 2004]. O acoplamento entre vizinhos tende a aproximar seus valores fazendo-os evoluir para uma configuração final, que pode ser um estado coerente, no qual todos os elementos da rede encontram-se sincronizados. Se o acoplamento não é forte o suficiente para conduzir a rede a um único estado coerente, ao menos o número de clusters tende a ser reduzido com o tempo. Estruturas espaciais menores (clusters menores) tendem a desaparecer com o aumento da intensidade do acoplamento [Kaneko, 1986]. Portanto, um controle exercido sobre os valores locais de acoplamento em pontos específicos pode alterar a dinâmica de toda a rede.

Se a auto-organização tende a reduzir a complexidade do sistema de mapas acoplados, a aplicação da lei de Hebb como política de controle dos acoplamentos locais tende a aumentar os efeitos da auto-organização. A idéia de como isso funciona é simples: a lei de Hebb aplicada ao sistema fortalece o acoplamento entre vizinhos com valores próximos e enfraquece o acoplamento entre vizinhos com valores mais distantes. Se, pelo princípio da autoorganização, vizinhos com valores próximos já tendem a se sincronizar devido ao acoplamento, a lei de Hebb pode vir a ser usada para controlar esse processo.

Mais adiante mostramos como a lei de Hebb pode servir de base para uma heurística de controle do processo de auto-organização de um mapa acoplado com a finalidade de conduzi-lo à obtenção de imagens segmentadas. 


\subsection{Analogia entre o neurônio artificial e o modelo logístico}

A figura (2.10) ilustra um neurônio biológico, composto por ramificações de dois tipos: um axônio, pelo qual se transmite um sinal para outros neurônios; e os dendritos, pelos quais que recebem sinais de axônios de outros neurônios. As interconexões neurais são conhecidas como sinapses.

Os neurônios artificiais são grafos direcionados [Haykin, 1994] como o da figura (2.11) com entradas ponderadas pelas sinapses, como no modelo biológico; sendo que a cada sinapse é atribuído um peso, cuja alteração do valor é responsável pelo aprendizado da rede. O produto escalar entre o vetor dos pesos sinápticos, $w$, e o vetor das entradas, $x$, é o argumento de uma função de ativação, $\varphi(\cdot)$, geralmente não-linear e monotonicamente crescente, que representa a saída ou resposta $y$ do neurônio. Assim:

$$
y=\varphi\left(\sum_{k=0}^{n} w_{k} \cdot x_{k}\right)
$$

sendo $n$ o número total de sinapses do neurônio em questão.

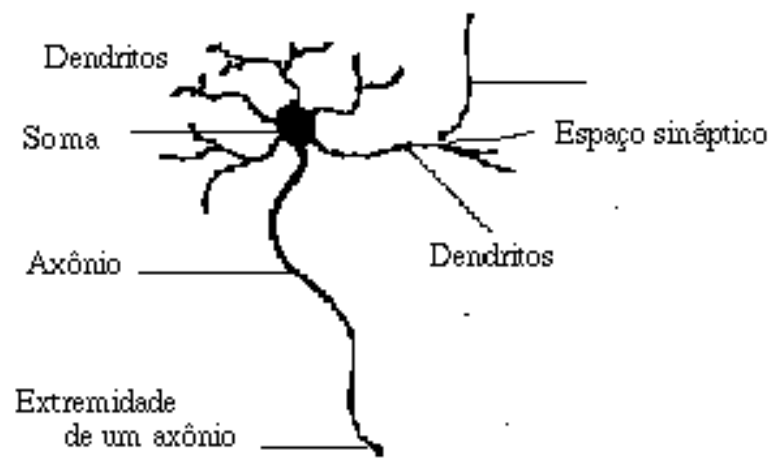

Figura 2.10 - Representação simplificada de um neurônio biológico. 


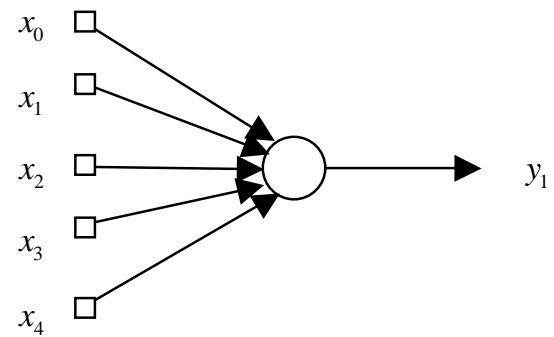

Figura 2.11 - Grafo representativo de um neurônio artificial.

Mapas, cuja dinâmica é baseada no modelo logístico de Verhulst, possuem características que sugerem forte analogia com neurônios artificiais de função de ativação do tipo sigmoidal. A função que caracteriza este tipo de neurônio é [Haykin, 1994]:

$$
\varphi(v)=\frac{1}{1+e^{-a \cdot v}}
$$

cuja derivada em relação à variável $v$ é:

$$
\frac{d \varphi(v)}{d v}=a \cdot \varphi(v) \cdot \frac{e^{-a \cdot v}}{1+e^{-a \cdot v}}
$$

ou:

$$
\frac{d \varphi(v)}{d v}=a \cdot \varphi(v) \cdot[1-\varphi(v)]
$$




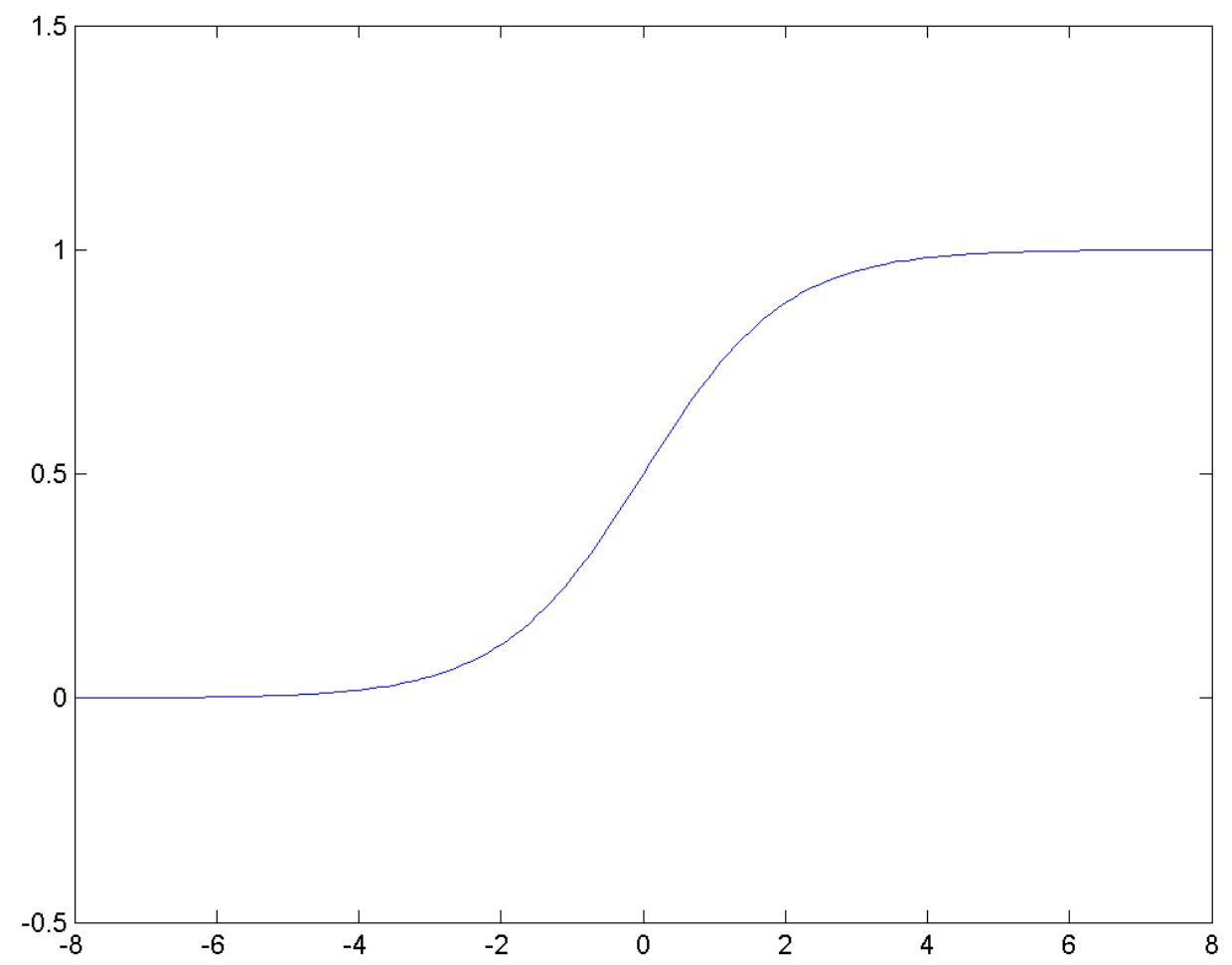

Figura 2.12 - Função sigmoidal típica, também conhecida como função logística.

A equação (2.10) nada mais é do que a equação de Verhulst apresentada no início deste capítulo. É devido a isso que a função sigmoidal também é chamada de função logística [Haykin, 1994]. A analogia faz algum sentido, porque a função de ativação de um neurônio deve apresentar saturação à medida que aumenta o somatório das entradas ponderadas pelos pesos sinápticos.

Sendo assim, a utilização de mapas acoplados com dinâmica logística como um modelo de abstração de alto nível para redes neurais é um argumento que possui certo grau de consistência. Essa é basicamente a justificativa pela qual, neste trabalho, mapas acoplados são utilizados para modelar redes de neurônios realizando processamento de imagens. 
De fato, mapas acoplados podem ser utilizados tanto para simular uma dinâmica populacional, como uma dinâmica neural [Kaneko, 1993], e também como modelos neurais no processamento de imagens [Kaneko, 1993; Leeuwen et al, 1997; Ruiz-del-Solar, 1998; Oliveira, 2004].

A auto-organização está relacionada à sincronização dos elementos da rede, que, no caso de sistemas biológicos, não precisam ser necessariamente células (como neurônios) de um único organismo. Sincronizam-se também: vaga-lumes machos, que picam simultaneamente para atraírem as fêmeas da vizinhança; grilos e gafanhotos que cricrilam em uníssono como estratégia de acasalamento; os ciclos menstruais de mulheres confinadas num internato; os aplausos de pessoas em salas de concerto húngaras e romenas; os ciclos de replicação, nos glóbulos vermelhos, dos protozoários causadores da malária [Monteiro, 2005].

\subsection{Segmentação de imagens}

Todo processamento ou busca de informação requer preliminarmente uma análise. Realizar uma análise é basicamente fragmentar um problema em outros menores que constituem o problema principal. Analisar a informação contida em um problema proposto é o primeiro passo para a sua posterior resolução, pois permite eliminar informações desnecessárias e classificar o que é importante. A técnica de análise costuma fazer uso do princípio "dividir e conquistar", pois separa um problema complexo em outros mais simples, facilitando o processamento por tratar de cada um individualmente. Esses problemas menores também podem ser organizados de modo a elaborar uma estratégia de seleção e sequiência do processamento das partes.

Segmentar um conjunto qualquer que contém informação nada mais é do que a separação desse em subconjuntos menores, e que individualmente apresentam uma complexidade menor do que o todo. Sendo assim, o primeiro 
passo em análise de imagens geralmente é a segmentação. A segmentação subdivide uma imagem em suas partes ou objetos constituintes; e o nível até o qual essa subdivisão deve ser realizada depende do problema a ser resolvido [Gonzalez e Woods, 1992].

A segmentação é um pré-processamento necessário para a interpretação de qualquer informação visual. Como pré-processamento subentende-se um passo preliminar imprescindível para o desempenho do posterior processamento. Além de segmentação, existem outros exemplos de préprocessamento de imagem, tais como filtragem de freqüência e equalização do histograma de níveis de cinza para imagens em preto e branco [Bow, 1992; Gonzalez e Woods, 1992]. Cada tipo de pré-processamento tem por objetivo tratar a informação bruta de modo a transformá-la em um formato que melhore o desempenho do processamento.

A título de exemplo, o leitor pode observar que neste texto, para facilitar a interpretação visual, existe sempre um espaço entre duas palavras. É uma disposição que simplifica a segmentação de informações no cérebro. Pode-se dizer, então, que a linguagem escrita já se encontra pré-processada, com o objetivo de facilitar o processamento da informação que ela contém.

Entretanto, a informação visual na natureza raramente surge de forma facilmente pronta a ser segmentada. O tratamento dessa informação é realizado pelas interconexões neurais no cérebro. Vale ressaltar que, mesmo para os animais, parece existir uma necessidade de haver uma seleção de padrões mais facilmente identificáveis em detrimento de outros: um animal terá mais facilidade de identificar, por exemplo, o seu alimento. Isso já leva intuitivamente à idéia da necessidade de uma possível correspondência entre segmentação e reconhecimento de padrões para um melhor desempenho de ambos. Um padrão de maior preferência tende a ser mais facilmente segmentado, e sua segmentação tende a torná-lo mais facilmente reconhecível. Por padrão subentende-se tanto forma, quanto textura, brilho e também sua cor. Um possível indício de como a sensação das cores pode ter surgido 
durante o processo de seleção natural para identificar padrões visuais é a cor vívida das frutas maduras em contraposição à cor verde que essas apresentam quando ainda estão com composição adstringente, dificultando assim a sua segmentação visual em meio às folhas das árvores por parte dos nossos antepassados.

Principalmente em projetos de sistemas de reconhecimento visual de padrões, é necessário preparar o procedimento de segmentação de modo a dar preferência aos padrões que devem ser detectados. Desse modo, é possível obter uma segmentação mais robusta. Em geral, a segmentação é uma das tarefas mais difíceis no processamento de imagens, e é o passo que determina o eventual sucesso ou fracasso na análise. De fato, uma segmentação efetiva quase sempre garante sucesso no reconhecimento [Gonzalez e Woods, 1992].

Segmentação é uma técnica de inferência que permite extrair informação de uma imagem. É, portanto, uma forma de abstração da imagem analisada, já que seleciona apenas a informação relevante para o posterior reconhecimento ou classificação. Sendo assim, a segmentação é geralmente o primeiro passo na análise de uma imagem, havendo, portanto um dilema para determinar o nível em que a subdivisão deve ser realizada. Esse é um problema que depende da natureza do problema que está sendo resolvido. Em um processo de automação de inspeção industrial, por exemplo, os parâmetros que caracterizam o nível de detalhamento desejado, a ser abstraído na segmentação, dependem das condições de iluminação ambiente, da natureza física do produto a ser inspecionado e de quais aspectos na sua estrutura são relevantes para uma classificação qualitativa do produto.

A detecção de descontinuidades é um passo fundamental no processo de segmentação. Através dela, pode-se determinar as possíveis fronteiras das partições que compõem uma imagem. A detecção de descontinuidades desdobra-se em três formas básicas: detecção de pontos, detecção de linhas e detecção de bordas. Naturalmente, a terceira é mais importante para um estágio inicial do processo de segmentação de uma imagem em níveis de 
cinza, porque detecta fronteiras em que a variação de intensidade ocorre de forma mais brusca. Geralmente a detecção de descontinuidades é realizada com a utilização de máscaras aplicadas sobre seus pontos. Essas máscaras têm a finalidade de caracterizar cada ponto em relação aos seus vizinhos. O cálculo da caracterização por máscaras é o produto escalar $R$ :

$$
R=\sum_{i=1}^{9} w_{i} \cdot z_{i}
$$

sendo que os valores $0 \leq z_{i} \leq 1$ são referentes aos pontos da imagem (tons de cinza) e os valores $w_{i} \in \mathrm{Z}$ são referentes aos pesos atribuídos às máscaras, como é mostrado nas figuras (2.13) e (2.14).

\begin{tabular}{|l|l|l|}
\hline$w_{1}$ & $w_{2}$ & $w_{3}$ \\
\hline$w_{4}$ & $w_{5}$ & $w_{6}$ \\
\hline$w_{7}$ & $w_{8}$ & $w_{9}$ \\
\hline
\end{tabular}

Figura 2.13 - Uma máscara 3x3 genérica

\begin{tabular}{|l|l|l|}
\hline$z_{1}$ & $z_{2}$ & $z_{3}$ \\
\hline$z_{4}$ & $z_{5}$ & $z_{6}$ \\
\hline$z_{7}$ & $z_{8}$ & $z_{9}$ \\
\hline
\end{tabular}

Figura 2.14 - Região de tamanho $3 \times 3$ de uma imagem. 
É interessante ressaltar que o produto escalar da equação (2.11) tem o mesmo formato que o argumento da equação (2.8), que descreve a função de ativação de um neurônio artificial. Portanto, podemos pensar na possibilidade de usar os valores das máscaras como se fossem pesos sinápticos em um modelo que simule interconexões neurais de processamento de imagens. A saída da função de ativação, sendo sigmoidal, pode em princípio inferir as características de cada ponto. A resposta mais forte expressa a máscara que melhor se ajusta a um ponto em questão.

O princípio básico de uma máscara de processamento de imagens é tentar classificar pontos através de seus pesos. Com esses pesos assumindo valores de sinais distintos em cada parte a ser classificada, uma inferência razoável pode ser obtida por meio de um produto escalar. A figura (2.15), por exemplo, por ser uma máscara para detecção de pontos, possui sinais distintos para o ponto central e seus vizinhos. A ponderação é calculada de modo que, quando todos os pontos têm o mesmo valor, o resultado da equação (2.11) seja nulo. Essa propriedade também pode ser verificada nas máscaras de detecção de linhas e bordas, ilustradas nas figuras (2.16) e (2.17).

\begin{tabular}{|c|c|c|}
\hline 0 & -1 & 0 \\
\hline-1 & 8 & -1 \\
\hline 0 & -1 & 0 \\
\hline
\end{tabular}

Figura 2.15 - Máscara característica para a detecção de pontos isolados.

\begin{tabular}{|c|c|c|}
\hline-1 & -1 & -1 \\
\hline 2 & 2 & 2 \\
\hline-1 & -1 & -1 \\
\hline
\end{tabular}

Horizontal

\begin{tabular}{|l|l|l|}
\hline-1 & -1 & 2 \\
\hline-1 & 2 & -1 \\
\hline 2 & -1 & -1 \\
\hline
\end{tabular}

$+45^{\circ}$

\begin{tabular}{|l|l|l|}
\hline-1 & 2 & -1 \\
\hline-1 & 2 & -1 \\
\hline-1 & 2 & -1 \\
\hline
\end{tabular}

Vertical

\begin{tabular}{|c|c|c|}
\hline 2 & -1 & -1 \\
\hline-1 & 2 & -1 \\
\hline-1 & -1 & 2 \\
\hline
\end{tabular}

$-45^{\circ}$

Figura 2.16 - Máscaras para a detecção de linhas. 


\begin{tabular}{|c|c|c|}
\hline-1 & -2 & -1 \\
\hline 0 & 0 & 0 \\
\hline 1 & 2 & 1 \\
\hline
\end{tabular}

(a) Gx

\begin{tabular}{|l|l|l|}
\hline-1 & 0 & 1 \\
\hline-2 & 0 & 2 \\
\hline-1 & 0 & 1 \\
\hline
\end{tabular}

(b) Gy

Figura 2.17 - Máscaras para a detecção de bordas.

As máscaras para detecção de bordas, apresentadas na figura (2.17), têm uma propriedade interessante: indicar a direção da variação de intensidade por meio do sinal do produto escalar. Isso se dá porque essas máscaras representam as derivadas espaciais de primeira ordem nas direções horizontal e vertical. São também chamadas de operadores de gradiente ou operadores de Sobel [Gonzalez e Woods, 1992].

No próximo capítulo, inicia-se uma discussão sobre complexidade e utilizamse mapas acoplados para detecção de simetria em imagens planas. 


\section{MAPAS ACOPLADOS: DETECÇÃO DE SIMETRIA}

\subsection{Comentários sobre trabalhos anteriores}

Mapas acoplados podem ter suas iterações controladas pelos valores dos parâmetros de modo a se obter um resultado desejado, tais como reconhecimento de padrões, detecção de certas propriedades espaciais em figuras planas, ou segmentação de imagens.

Quanto ao uso de redes de mapas acoplados com finalidade de estudo de padrões, diversos trabalhos já foram feitos, tais como para reconhecimento de padrões espaciais, como em deMaris [2003], em que é usado um modelo de variação intermitente de parâmetros baseado no princípio "amostrar e interagir" (princípio através do qual o autor especula que pode formar as ondas cerebrais) e o índice de desempenho do reconhecimento é correlacionado com a entropia informacional do padrão.

Para segmentar e reconhecer figuras faz-se necessário avaliar a sua complexidade. Resta então a pergunta: como definir complexidade? Existem diversas maneiras de se avaliar complexidade, sendo que a entropia informacional é apenas uma delas. Pode-se dizer que uma matriz de elementos é mais complexa, possuindo uma maior entropia, quando o histograma de seus estados possíveis é mais uniforme ao longo de um espectro. Um exemplo de proposta de medida de complexidade pode ser visto em Sánchez [2005], que é baseada numa composição de entropia com a variância dos estados dos mapas que compõem a matriz. Sendo $p_{i}$ a probabilidade de encontrar um determinado nível quantizado, a complexidade $C(\bar{p})$ é medida como o produto da entropia $H(\bar{p})$ com uma medida de desequilíbrio $D(\bar{p})$ da seguinte forma:

$$
C(\bar{p})=H(\bar{p}) \cdot D(\bar{p})=-k \cdot\left(\sum_{i=1}^{N} p_{i} \cdot \log p_{i}\right) \cdot\left(\sum_{i=1}^{N}\left(p_{i}-1 / N\right)^{2}\right)
$$


sendo $i$ o índice associado a um nível existente no mapa acoplado; $p_{i}$ a probabilidade de ocorrência desse nível; $N$ o número de níveis distintos e $k$ uma constante.

O objetivo da segmentação é reduzir a complexidade de uma imagem de tal forma a minimizar a informação a ser posteriormente processada. No caso em que a entropia é máxima, portanto, tem-se $p_{i}=1 / N$ para todo $i$, o que resulta num desequilíbrio nulo e, consequentemente em uma complexidade zero. Enquanto a entropia avalia a distribuição de um histograma, o índice de desequilíbrio mede a tendência de concentração do histograma em torno de algumas regiões. A equação (3.1) é então intuitivamente aceitável como uma medida de complexidade de imagens segmentadas, porque mapas acoplados tendem a possuir uma perda de sincronismo entre elementos de clusters distintos, enquanto elementos de um mesmo cluster tendem a se sincronizar, assumindo valores próximos. Por ser o produto da entropia informacional por um desvio quadrático, a equação (3.1) de fato mede o grau de espalhamento de um histograma de níveis de cinza. Entretanto, esse índice não considera o quanto dois valores de níveis distintos estão próximos o suficiente para estar sincronizados em um mesmo cluster ou não. Apenas as frequiências relativas de cada um dos níveis são levadas em consideração.

Quanto à segmentação, diversos trabalhos já foram feitos, baseando em iterações competitivas entre elementos vizinhos, tais como os de Zhao e Macau [2001] e Leeuwen et al [1997]. Nesses artigos, são mostradas tanto técnicas numéricas quanto analíticas. O princípio da iteração competitiva consiste em fazer com que elementos acoplados que constituem um mesmo segmento da imagem funcionem como osciladores e entrem em sincronização. $\mathrm{O}$ primeiro modela $\mathrm{O}$ processo de segmentação de tal forma a maximizar o número de figuras planas não sobrepostas a serem segmentadas em uma imagem. Como forma de avaliar o sincronismo formado pela dinâmica, foi utilizado o desvio-padrão instantâneo $v(t)$, que indica a distância no espaço euclidiano em relação à média $m(t)$ dos mapas de um segmento, e $v$ é o erro cumulativo dos valores de $v(t)$. 
Assim:

$$
\begin{aligned}
& m(t)=\frac{1}{N} \cdot \sum_{i=1}^{N} x_{i}(t) \\
& v(t)=\frac{1}{N} \cdot \sqrt{\sum_{i=1}^{N}\left(x_{i}(t)-m(t)\right)^{2}} \\
& v=\frac{1}{T} \cdot \sum_{t=T_{o}}^{T_{o}+T} v(t)
\end{aligned}
$$

sendo $i$ o índice associado a um nível existente no mapa acoplado; $x_{i}$ o valor do nível associado ao índice $i$; e $N$ o número de níveis distintos.

O valor de $v(t)$ tende a zero à medida que os mapas entram em sincronização. E o valor de $v$ pode funcionar como um índice de desempenho do processo de segmentação. Constatou-se que quanto maior o raio da vizinhança de elementos com acoplamento local e que quanto mais forte o acoplamento, menor o valor de $v$ [Zhao e Macau, 2001]. Para valores do raio $R$ e do acoplamento $\varepsilon$ a partir de um determinado limiar, tem-se $v=0$.

Leeuven et al [1997] investigaram o surgimento de padrões complexos a partir de sistemas simples. O parâmetro de bifurcação e o coeficiente de acoplamento são relacionados com o tipo de regime permanente obtido. Constatou-se que o caos tende a ser mais fracamente suprimido se o número de clusters for muito elevado. De fato, um grande número de clusters tende a estar relacionado com uma complexidade informacional maior e indica que o sincronismo é fraco. É feita uma analogia entre mapas acoplados e filtros, seguindo a heurística de aumentar o acoplamento em regiões onde há pouca variação no valor dos mapas. É utilizada uma matriz dinâmica de acoplamento em vez de um único valor escalar para o acoplamento. Nessa matriz, cada elemento, que representa o acoplamento entre dois 
mapas, é uma função sigmoidal do módulo da diferença dos valores instantâneos desses mapas.

\subsection{Modelo desenvolvido: heurísticas e resultados}

Métodos para identificar e reconhecer imagens, através da atividade síncrona exibida por redes de mapas acoplados, vêm sendo investigados por vários autores. Esses métodos têm como inspiração o processamento de sinais sensoriais realizado por neurônios corticais [e.g. Singer e Gray, 1995]. Sincronismo é, de fato, um comportamento dinâmico encontrado em nosso córtex, além de em muitos outros sistemas biológicos e eletrônicos [e.g. Monteiro, 2003; Monteiro et al, 2003]. E tal comportamento pode ser útil na resolução de tarefas computacionais. Por exemplo, Oliveira e Monteiro [2002] e Oliveira [2004] propuseram usar redes de mapas acoplados a fim de que o sincronismo entre as atividades dos mapas fosse indicador de alguma característica geométrica da imagem. Em particular, a topologia de acoplamento entre os elementos da rede foi escolhida de modo que a sincronização entre eles ocorre somente na presença de simetria especular na imagem apresentada à rede.

Simetria é um conceito amplo, podendo ser associado a qualquer sistema no qual exista a possibilidade de se efetuar mudança mantendo certos aspectos inalterados. No caso especial de um plano em $R^{2}$, é possível identificar dois tipos de simetria:

- Simetria especular ou de reflexão: Uma figura em $R^{2}$ apresenta simetria de reflexão quando quaisquer dois pontos que pertencem a uma reta ortogonal ao eixo de simetria, estando cada um deles de um lado do eixo de simetria e à mesma distância dele, têm o mesmo valor. 
- Simetria radial ou de rotação: Ocorre quando a figura em $R^{2}$ é invariante a uma determinada rotação de um ângulo $\theta$ tal que $\theta=2 \cdot \pi / k$ sendo $k \in N$ a ordem da simetria.

Aqui, interessa o estudo de simetria de reflexão, na qual é possível a transformação $T_{(r)}(x, y)=(-x, y)$ para a qual o eixo de simetria vertical é o eixo y.

Existem diversos métodos para obtenção de simetria, porém poucos são baseados em modelos de redes de mapas. A razão disso é fato de que a detecção de simetria é geralmente um problema combinatório em que a complexidade cresce exponencialmente com o número de elementos da imagem. Sendo assim, faz-se necessário um modelo de detecção no qual a arquitetura da rede possua uma estrutura específica para o problema em questão tornando-a menos ampla que um modelo geral de detecção de imagens [Oliveira, 2004].

O uso de mapas acoplados permite representar relações espaciais entre os elementos da rede. Ou seja, o estado de qualquer elemento é função tanto do tempo quanto de sua localização na rede. E é essa propriedade dos mapas acoplados que pode ser utilizada para abstrair certas relações espaciais como, por exemplo, a simetria.

Os mapas acoplados têm a propriedade de atingir um estado assintoticamente estável na presença de sincronismo entre todos os elementos que interagem entre si. O acoplamento entre os elementos pode ser global, local, ou ainda uma mistura de ambos.

No modelo proposto por Oliveira e Monteiro [2002] e Oliveira [2004], a equação do acoplamento de mapas foi adaptada para se detectar simetria em imagens planas. Assim, a equação do mapa acoplado foi escrita como: 


$$
x_{i}(t+1)=(1-\varepsilon) \cdot f_{\mu}\left(x_{i}(t)\right)+\frac{\varepsilon}{N} \cdot \lambda\left(x_{i}(t)\right) \cdot \sum_{j=1}^{N} f_{\mu}\left(x_{j}(t)\right)+I_{i}(t)
$$

sendo $\varepsilon$ o acoplamento local; $i$ o índice associado ao mapa $x_{i}(t)$ sob domínio do tempo discreto $t ; f_{\mu}$ a função que caracteriza o mapa logístico e $N$ o número de mapas iterativos que compõem a rede.

As entradas externas $I_{i}(t)$ representam o valor de cada pixel da imagem. É importante notar que essa entrada pode ser uma função do tempo. É possível então fornecer para a rede uma imagem que se modifica no tempo, enquanto os mapas interagem simultaneamente. Também foi introduzido um acoplamento local $\lambda\left(x_{i}(t)\right)$ que é o termo que representa a relação espacial entre os mapas que garante a detecção da simetria. Em um modelo misto em que coexistem os acoplamentos global e local, as conexões globais tendem a tornar o sincronismo mais fácil de ser alcançado e as conexões locais buscam representar certas propriedades espaciais.

Vale ressaltar que, nesse caso, o acoplamento local não indica necessariamente um acoplamento entre mapas vizinhos: para detectar simetria faz-se necessário um acoplamento também entre mapas diametralmente opostos, isto é, cujas posições são simétricas em relação ao eixo de simetria definido.

A equação (3.5) representa uma rede unidimensional. Para o estudo de imagens bidimensionais as seguintes modificações são necessárias:

$$
x_{i, j}(t+1)=(1-\varepsilon) \cdot f_{\mu}\left(x_{i, j}(t)\right)+\frac{\varepsilon}{N} \cdot \lambda\left(x_{i, i}(t)\right) \cdot \sum_{i=1}^{m} \sum_{j=1}^{m} f_{\mu}\left(x_{i, j}(t)\right)+I_{i, i}(t)
$$

sendo que agora consideram-se as imagens como matrizes quadradas $m \times m$, e cada mapa é uma variável de estado $x_{i, j}(t)$ e está associado ao pixel da linha $i$ e da coluna $j$. 
Nesse modelo, coexistem acoplamentos global e local, de sorte que as conexões globais tendem a encurtar o transiente relacionado à solução síncrona [e.g. Wang e Chen, 2002] e as conexões locais buscam capturar certas relações geométricas da imagem. Definiu-se esse termo de acoplamento como:

$$
\lambda\left(x_{i, j}(t)\right)=x_{i, j}(t) \cdot x_{i, m-j+1}(t)+\Delta x_{i, j}(t)
$$

sendo que o produto representa a correlação entre pixels diametralmente opostos e a segunda parcela, $\Delta x_{i, j}$, é o operador laplaciano, que representa a propagação local.

Esse operador laplaciano pode ser obtido da seguinte forma:

$$
\Delta x_{i, j}(t)=x_{i+1, j}(t)+x_{i-1, j}(t)+x_{i, j+1}(t)+x_{i, j-1}(t)-4 \cdot x_{i, j}(t)
$$

A equação (3.8) pode ser deduzida aplicando a definição usual de operador laplaciano em um espaço contínuo para um espaço discreto e a definição de derivada parcial:

$$
\begin{aligned}
& \nabla^{2} x(i, j)=\frac{\partial^{2} x(i, j)}{\partial i^{2}}+\frac{\partial^{2} x(i, j)}{\partial j^{2}} \\
& \frac{\partial x(i, j)}{\partial i}=\lim _{\Delta i \rightarrow 0} \frac{x(i+\Delta i, j)-x(i, j)}{\Delta i} \\
& \frac{\partial x(i, j)}{\partial i}=\lim _{\Delta i \rightarrow 0} \frac{x(i, j)-x(i-\Delta i, j)}{\Delta i}
\end{aligned}
$$

Aplicando (3.10a) na primeira parcela do segundo membro de (3.9): 
$\frac{\partial^{2} x(i, j)}{\partial i^{2}}=\frac{\partial}{\partial i}\left(\frac{\partial x(i, j)}{\partial i}\right)=\frac{\partial}{\partial i}\left(\lim _{\Delta i \rightarrow 0} \frac{x(i+\Delta i, j)-x(i, j)}{\Delta i}\right)=\lim _{\Delta i \rightarrow 0} \frac{1}{\Delta i} \cdot\left[\frac{\partial x(i+\Delta i, j)}{\partial i}-\frac{\partial x(i, j)}{\partial i}\right]$

e, aplicando (3.10b):

$$
\begin{gathered}
\frac{\partial^{2} x(i, j)}{\partial i^{2}}=\lim _{\Delta i \rightarrow 0} \frac{1}{\Delta i} \cdot\left[\frac{x(i+\Delta i, j)-x(i+\Delta i-\Delta i, j)}{\Delta i}-\frac{x(i, j)-x(i-\Delta i, j)}{\Delta i}\right] \\
\frac{\partial^{2} x(i, j)}{\partial i^{2}}=\lim _{\Delta i \rightarrow 0} \frac{x(i+\Delta i, j)+x(i-\Delta i, j)-2 \cdot x(i, j)}{\Delta i^{2}}
\end{gathered}
$$

Analogamente:

$$
\frac{\partial^{2} x(i, j)}{\partial j^{2}}=\lim _{\Delta i \rightarrow 0} \frac{x(i, j+\Delta j)+x(i, j-\Delta j)-2 \cdot x(i, j)}{\Delta j^{2}}
$$

Somando (3.11a) e (3.11b) temos o laplaciano. Substituindo em (3.9):

$$
\begin{aligned}
\nabla^{2} x(i, j)= & \lim _{\Delta i \rightarrow 0} \frac{x(i+\Delta i, j)+x(i-\Delta i, j)-2 \cdot x(i, j)}{\Delta i^{2}}+ \\
& \lim _{\Delta j \rightarrow 0} \frac{x(i, j+\Delta j)+x(i, j-\Delta j)-2 \cdot x(i, j)}{\Delta j^{2}}
\end{aligned}
$$

No domínio discreto, a variação mínima para $\Delta i$ e $\Delta j$ vale um. Substituindo $\Delta i$ e $\Delta j$ por 1 , o laplaciano contínuo $\nabla^{2} x(i, j)$ torna-se o laplaciano discreto $\Delta x_{i, j}$ Daí, segue a expressão definida em (3.8).

Como medidas do sincronismo que detecta a simetria, usamos as seguintes variáveis definidas por Oliveira e Monteiro [2002]: 


$$
\begin{aligned}
& y_{i}(t)=\sum_{j=1}^{m}\left|x_{i, j}(t)-x_{i, m-j+1}(t)\right| \\
& z(t)=\sum_{j=1}^{m} y_{i}(t)
\end{aligned}
$$

sendo que (3.12) expressa o sincronismo de cada linha separadamente e (3.13) o sincronismo total da figura. Para uma a imagem simétrica, $z(t)$ vale zero.

Nas simulações de Oliveira [2004], foram usados os parâmetros $\mu=3,5$ para o mapa logístico, $\varepsilon=0,6$ para o acoplamento e estados iniciais de cada mapa no intervalo [0 0,01] distribuídos aleatoriamente. Pixels assumindo valores de 0 a 255 numa escala de cinzas e as entradas $I_{i, j}$ também no intervalo [0 0,01]. Essa escolha para o intervalo foi feita como uma tentativa de impedir que a expressão (3.6) divirja.

Apesar de no trabalho original de Oliveira [2004] ter sido usada a fórmula (3.6), foi verificado experimentalmente que mesmo para valores iniciais pequenos, da ordem de 0,01 os resultados podiam divergir em algum momento. O laplaciano de algum mapa acabava resultando num número negativo, o que por sua vez pode fazer com que (3.7) e (3.6) resultem em números negativos. Com o valor do mapa da interação seguinte sendo negativo o sistema começa a divergir para menos infinito, o que o caracteriza como instável. Pelo visto, limitando a faixa de valores iniciais em valores muito baixos a divergência é apenas adiada, mas não corrigida.

Aqui, neste nosso trabalho, é proposta uma nova fórmula para substituir (3.6) que limite todos os mapas logísticos no intervalo [0 1] e que seja capaz de interagir com a imagem de entrada $I_{i, j}$. No caso em que $I_{i, j}$ possua uma figura simétrica ou não, mas deslocada do eixo de simetria central foi desenvolvido um algoritmo que busca centralizar a imagem dinamicamente enquanto se busca detectar a simetria.

Como uma alternativa ao sistema de equações (3.6), propomos as seguintes equações [Rizzo et al, 2005]: 


$$
\begin{aligned}
& \begin{array}{l}
x_{i, j}(t+1)=(1-\alpha)\left((1-\varepsilon) f_{\mu}\left(x_{i, j}(t)\right)+\frac{\varepsilon}{N} \cdot \varphi\left(x_{i, i}(t)\right) \cdot \sum_{i=1}^{m} \sum_{j=1}^{m} f_{\mu}\left(x_{i, j}(t)\right)\right) \\
+\alpha \cdot I_{i, i}(t)
\end{array} \\
& \varphi\left(x_{i, i}(t)\right)=x_{i, i}(t) x_{i, m-i+1}(t)\left(1-\tanh \left(\frac{\Delta x_{i, j}(t)}{4}\right)\right)
\end{aligned}
$$

sendo que $\alpha$ é a constante de acoplamento da imagem de entrada, $\varphi\left(x_{i, i}(t)\right)$ é o novo termo de acoplamento local e os outros termos são os mesmos da equação (3). Como agora existem duas constantes de acoplamento no intervalo [0 1$]$, e a função sigmoidal tangente hiperbólica limita o laplaciano, a expressão (3.14) é impedida de divergir. A simetria continua sendo mensurada conforme (3.12) e (3.13).

Como uma rede de mapas acoplados é um sistema dinâmico, a entrada $I_{i, j}(t)$ pode variar no tempo, mas o sistema apenas pode estabilizar em algum regime permanente depois que a entrada pára de variar no tempo. Esta propriedade de sistemas dinâmicos pode ser utilizada para detectar simetria numa figura não centralizada na imagem, deslocando-a até obter o máximo de simetria possível, fazendo uso do coeficiente $z(t)$ como uma variável de controle.

Uma figura simétrica em relação ao eixo vertical central está centralizada ou "equilibrada" dentro da imagem, apesar de uma figura centralizada não ser necessariamente simétrica. Associando o valor de cada pixel numa imagem de níveis de cinza a um peso pode-se chegar intuitivamente na idéia de que uma figura possui um baricentro na imagem na qual está contida. O baricentro é capaz de indicar o quanto a imagem está deslocada do eixo vertical e em que lado do eixo ela está mais concentrada.

O baricentro da imagem relativo ao eixo central pode ser definido por [Rizzo et al, 2005]: 


$$
\varpi(t)=\frac{\sum_{i=1}^{m} \sum_{j=1}^{m} x_{i, j}(t) \cdot j}{\sum_{j=1}^{m} x_{i, j}(t)}-\left(\frac{m+1}{2}\right)
$$

Para o cálculo do deslocamento da imagem a ser corrigida, fazemos uso da seguinte fórmula:

$$
\delta(t)=\tanh (z(t) \cdot \varpi(t))
$$

O valor de $\delta(t)$ é arredondado para $-1,0$ ou +1 conforme seu sinal.

Um exemplo de aplicação prática é o encaixe automático de um eixo dentro de um mancal, como pode ser visto na figura (3.1). Foi feita uma simulação desse exemplo prático como pode ser visto adiante. Nessa simulação, em vez de deslocar toda a imagem a cada passo, é mantido o plano de fundo com a projeção superior do mancal enquanto o eixo se move até atingir sincronismo total.

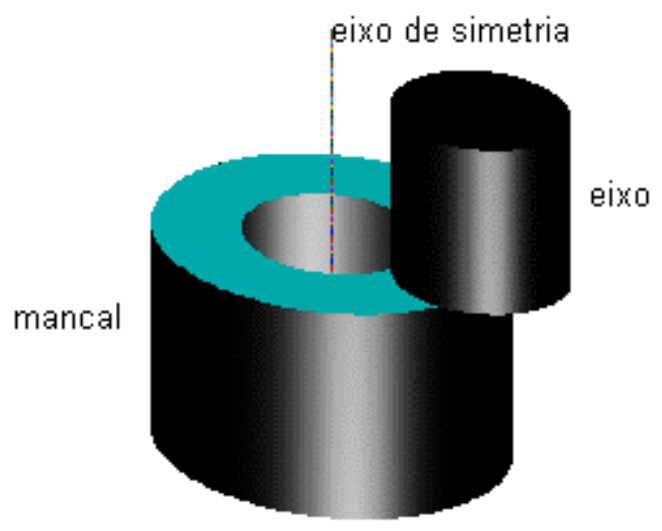

Figura 3.1 - Visualização da possível aplicação prática.

Sistemas dinâmicos de tempo discreto, relacionados à detecção de simetria [Oliveira e Monteiro, 2002; Oliveira; 2004; Rizzo et al, 2005] apresentam fácil implementação computacional e podem ser usados em sistemas de controle de posição. Aqui, desenvolvemos uma rede de mapas acoplados que, dinamicamente, verifica a existência de simetria especular, via sincronismo da atividade dos mapas, 
e usa essa informação para realizar a tarefa de controle em questão. Implementamos um esquema que desloca a imagem ao longo do eixo horizontal, até se obter sua centralização. As figuras (3.2a) e (3.2b) mostram por meio de uma simulação como esse processo pode vir a ser feito.
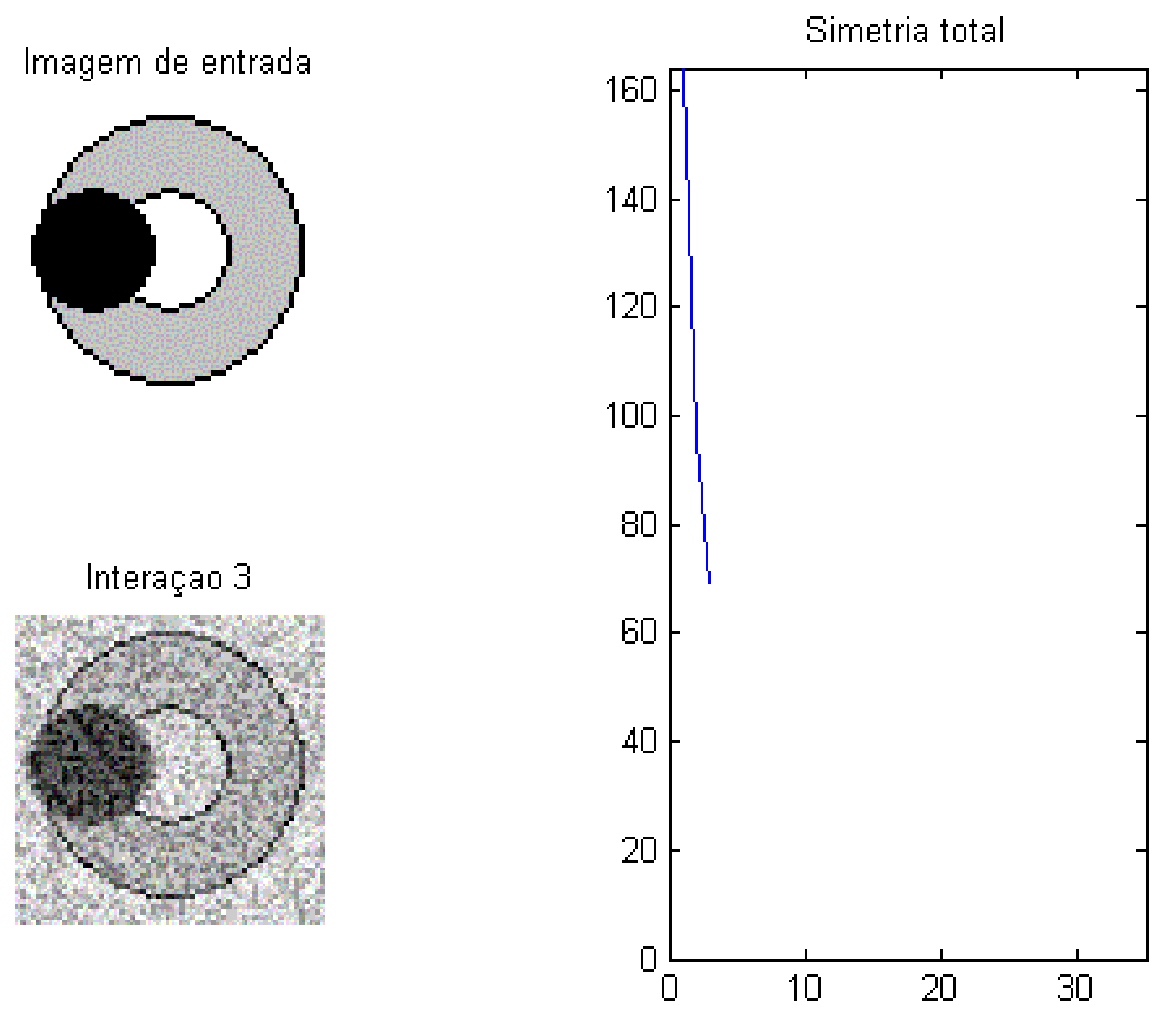

Figura 3.2a - Simulação de um encaixe mecânico em um estado transitório (peça ainda não alinhada). A figura superior esquerda representa a entrada (informação extraída do meio externo); a inferior esquerda a evolução em dinâmica acoplada; e a direita o gráfico do coeficiente de assimetria $z(t)$. 

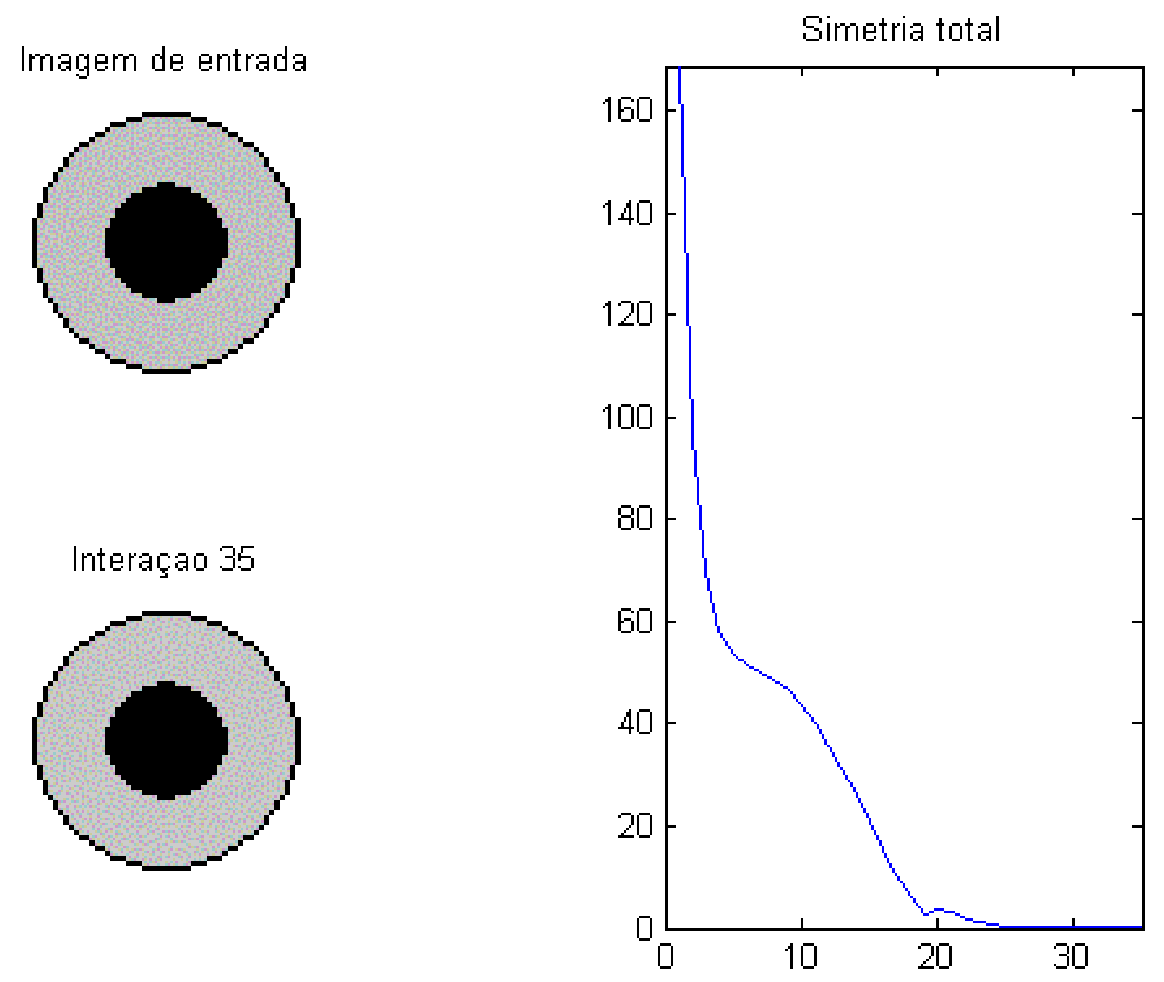

Figura 3.2b - Simulação de um encaixe mecânico no estado final (peça alinhada). A figura superior esquerda representa a entrada (informação extraída do meio externo); a inferior esquerda a evolução em dinâmica acoplada que agora encontra-se sem perturbação; e a direita o gráfico do coeficiente de assimetria $z(t)$, que converge assintoticamente para zero.

Vale ressaltar que, por ser uma derivada de segunda ordem, o operador laplaciano, cuja máscara é mostrada na figura (3.3), não é muito indicado para detectar variações de intensidade em bordas, pois é incapaz de predizer a direção da borda e tende a amplificar muito o ruído [Gonzalez e Woods, 1992].

\begin{tabular}{|c|c|c|}
\hline 0 & -1 & 0 \\
\hline-1 & 8 & -1 \\
\hline 0 & -1 & 0 \\
\hline
\end{tabular}

Figura 3.3 - Máscara característica do operador laplaciano discreto.

No próximo capítulo, usam-se mapas acoplados para segmentação de imagens. 


\section{MAPAS ACOPLADOS: SEGMENTAÇÃO DE IMAGENS}

\subsection{Conceitos preliminares}

O conceito de segmentação de imagens monocromáticas é baseado em duas propriedades básicas de valores de níveis de cinza: descontinuidade e similaridade [Gonzalez e Woods, 1992]. A primeira permite particionar a imagem baseando-se em mudanças bruscas nos níveis de cinza, detectando linhas de contorno. A segunda possibilita equalizar níveis muito próximos, pois com isso segue-se a heurística de que pixels vizinhos com níveis muito próximos provavelmente fazem parte de uma mesma partição da imagem analisada.

Portanto podemos conjecturar que a segmentação é, basicamente, uma forma de filtragem de freqüência no domínio do espaço bidimensional que contém a imagem. Porém, essa filtragem deve oferecer tanto características de passa-altas, para detectar os contornos; quanto de passa-baixas, para equalizar as regiões contidas no interior dos contornos. Ou seja, a descontinuidade a ser obtida com a segmentação tende a deixar o espectro de freqüência espacial mais largo, enquanto a similaridade obtida tende a reduzir a entropia informacional da imagem.

Mapas acoplados oferecem a possibilidade de segmentação de imagens, pois também possuem analogia com filtros. A formação de clusters é a evidência clara desta propriedade. Clusters são aglutinações de mapas vizinhos que entram em sincronia, equalizando-se entre si. Além disso, os clusters são limitados por variações espaciais bruscas do nível de cinza. Concluindo, clusters são partições segmentadas que surgem espontaneamente em mapas acoplados com dinâmica não linear.

A difusão tende a homogeneizar o sistema, enquanto a dinâmica caótica insere uma tendência à não-homogeneização devido à sensibilidade às condições iniciais. Essas duas tendências entram em conflito uma contra a outra, fazendo com que o caos seja mais forte em alguns domínios, enquanto a ordem é mais forte em outros 
[Kaneko, 1993]. Surgem então regiões aproximadamente homogêneas, os clusters, cercadas por mapas com estados em valores muito discrepantes da faixa de valor dos elementos desse cluster.

Podemos também considerar um cluster como sendo um segmento de uma rede de mapas acoplados. Os mapas localizados na fronteira de um cluster fazem parte do domínio do caos, possuindo uma tendência à descontinuidade. Os mapas localizados no interior de um cluster têm uma dinâmica de auto-organização, possuindo uma tendência à similaridade. Como visto, descontinuidade $\mathrm{e}$ similaridade entre elementos vizinhos definem a segmentação.

O acoplamento entre os elementos, geralmente, é tal que influi com uma tendência de homogeneização provocada pela difusão que contribui para a aproximação de mapas interconectados. Já a não-linearidade e a dinâmica caótica têm uma influência de imprevisibilidade e distanciamento dos valores instantâneos dos mapas. Se esses fossem lineares, o comportamento assintótico sempre levaria a uma homogeneidade ou coerência; pois sistemas lineares cujos valores são aproximados por um acoplamento tendem a continuar se aproximando. Para mapas não lineares, entretanto, se dois ou mais mapas com acoplamento estão com seus valores instantâneos próximos, não há garantia alguma de que nas próximas iterações vão tender para um mesmo valor. Eles podem entrar em sincronia ou não. Isso ocorre graças à possibilidade de haver sensibilidade da trajetória dinâmica de mapas com dinâmica não linear a pequenas variações no seu estado.

É do conflito dessas duas tendências que surgem os estados ordenados de mapas acoplados não-lineares, com a formação de clusters, que são regiões em que conjuntos de mapas vizinhos estão momentaneamente sincronizados. Podemos então fazer uma analogia entre a lei de Hebb e mapas acoplados, já que a sincronização entre mapas vizinhos pode ser considerada uma associação enquanto a dessincronização uma dissociação. A formação de clusters é uma evidência de que a lei de Hebb pode ser aplicar em mapas acoplados com dinâmica não-linear.

Uma vez que uma estrutura atinge a supressão do caos, o conflito é resolvido e essa estrutura atinge a estabilidade. Kaneko [1993] expõe a conjectura de que esse 
fenômeno ocorre porque uma estrutura com os menores expoentes de Lyapunov tende a ser naturalmente selecionada durante a evolução da dinâmica do sistema. Se a auto-organização tende a funcionar como um regime permanente, então podemos fazer uso dessa propriedade para inferir uma regra de controle que possibilite a um CML evoluir de modo a estabilizar-se numa figura segmentada referente a uma imagem inicialmente fornecida.

A figura (4.1) ilustra a conjectura intuitiva do conceito de como seria possível fazer uma analogia entre redes de mapas acoplados e filtros de frequiência espacial. A figura (4.2) ilustra uma rede de mapas acoplados com elementos vizinhos sincronizando-se e formando diversos clusters. Os acoplamentos global e local escolhidos são altos o suficiente para que exista uma alta difusão, o que implica a existência de certa uniformidade de níveis de cinza no interior de cada cluster. Já o valor alto do parâmetro de bifurcação, escolhido numa região caótica, resulta numa alta sensibilidade a pequenas diferenças entre mapas vizinhos, o que implica variações bruscas nas bordas de cada cluster.

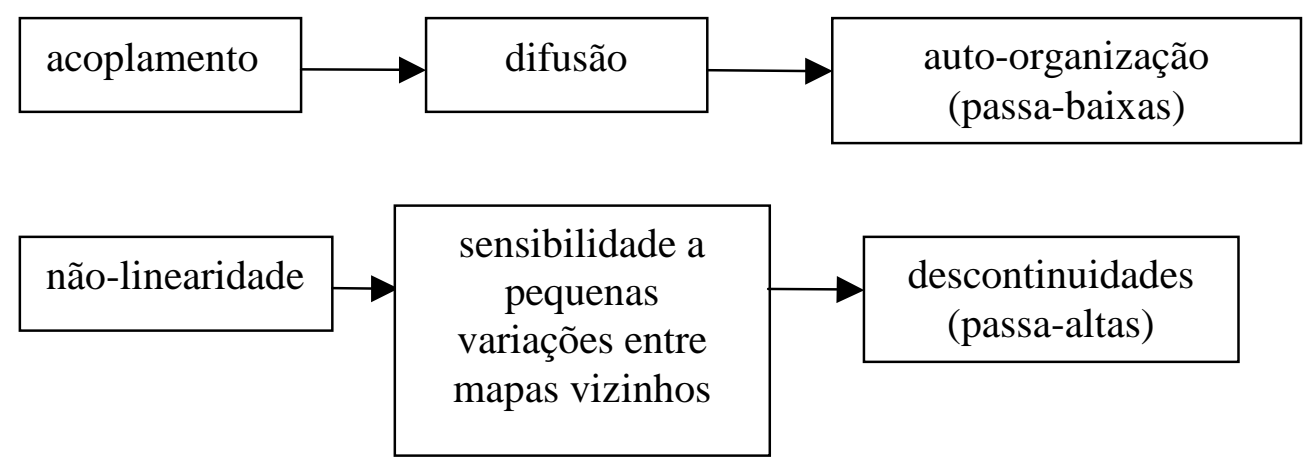

Figura 4.1 - Analogia entre mapas acoplados e filtros de freqüência. 


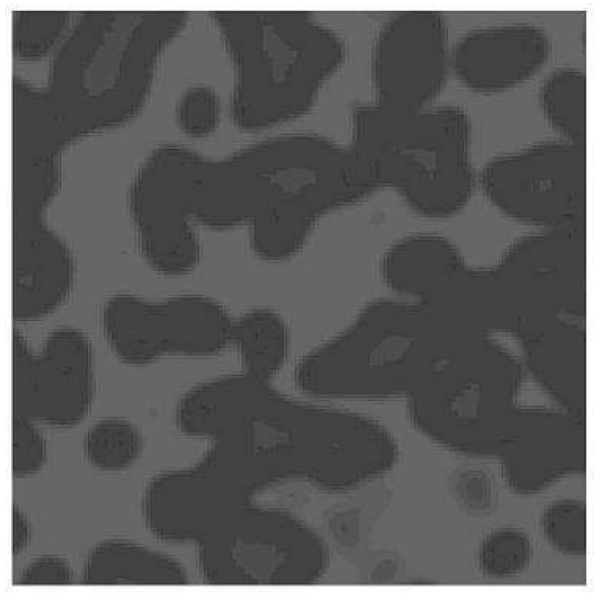

Figura 4.2 - Rede bidimensional de mapas acoplados com formação de clusters com acoplamentos global e local de 0,3 e 0,8 respectivamente, e parâmetro de bifurcação 3,8 , fazendo uso do mapa logístico da equação (2.4).

No caso da figura (4.2) o acoplamento é forte o suficiente para que existam poucos níveis distintos, o que atribui uma baixa entropia à rede.

É conveniente apresentar um segundo gráfico juntamente com a rede de mapas, mostrando o grau de espalhamento da informação contida na rede. A figura (4.3) mostra uma rede de mapas acoplados acompanhada de seu histograma de níveis de cinza. O eixo horizontal do histograma associa os valores numéricos de 0 a 1 dos mapas (ou seja, o valor da variável $x$ desses mapas) a respectivos tons de cinza numa escala em degrade. Podem-se observar, no gráfico da esquerda, clusters mais claros que correspondem no histograma à banda da direita (com dois picos altos) com maior freqüência de ocorrências. Já a banda da esquerda (cujos tons de cinza são menos claros) representa o "plano de fundo" composto por uma distribuição de tons intermediários de cinza (banda larga central no histograma) com pequenos clusters mais escuros, sendo esses caracterizados pelo estreito pico da esquerda na banda central do histograma. 

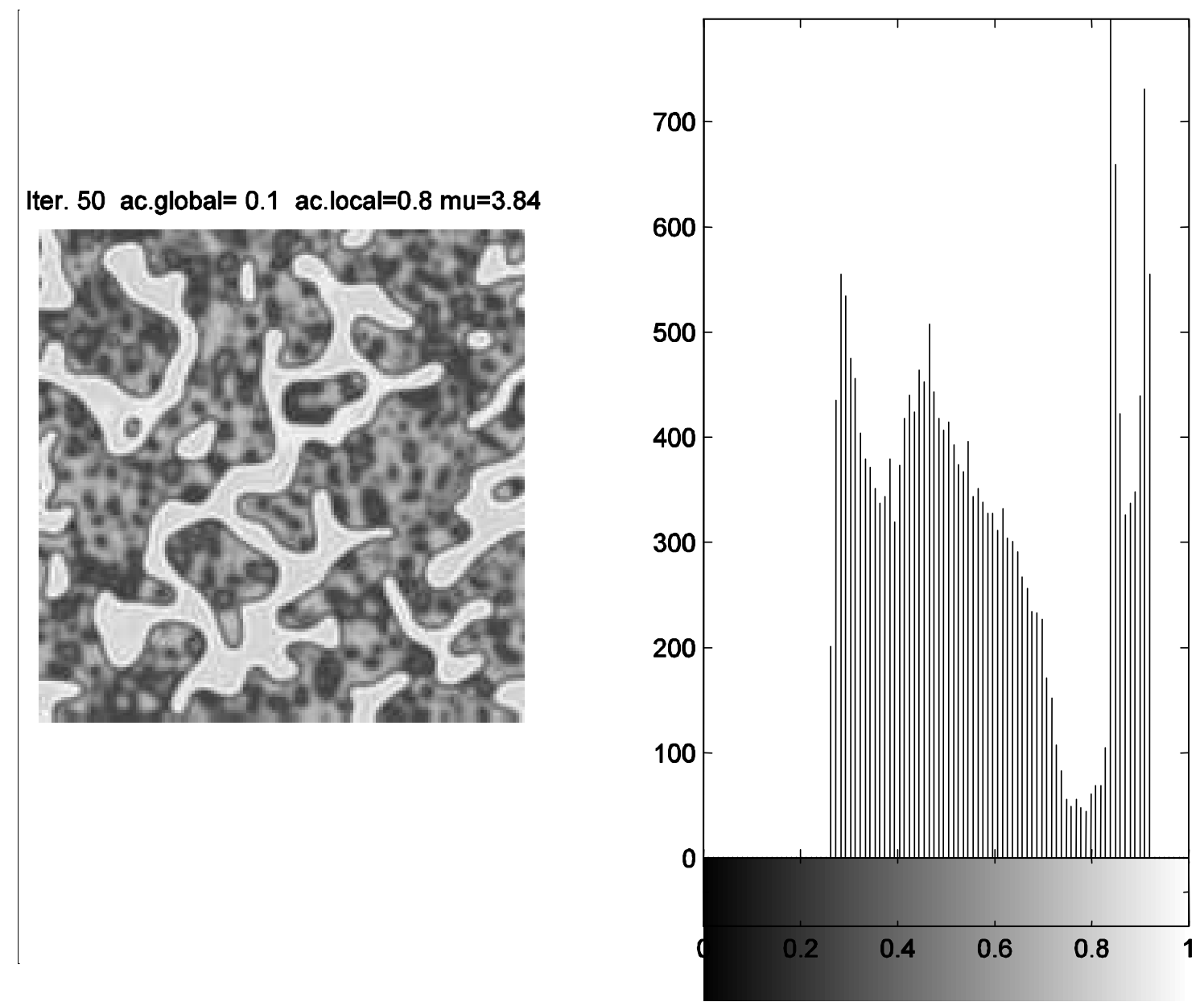

Figura 4.3 - Rede bidimensional de mapas acoplados com formação de clusters com acoplamentos global e local de 0,1 e 0,8 respectivamente e parâmetro de bifurcação 3,84 acompanhado de seu histograma de níveis de cinza, usando o mapa logístico.

Note que, no histograma acima, não há ocorrência de níveis de cinza abaixo de 0,26 e nem acima de 0,93. Isso acontece porque, analisando o diagrama de bifurcação do mapa logístico (mostrado na figura (2.4)), verifica-se que existe um intervalo em $x$ que limita o domínio dessa variável no regime permanente. Por exemplo, para $\mu=3,84$ tem-se que $x$ assintótico está entre 0,26 e 0,93 .

O problema em aplicar mapas acoplados em segmentação de imagens consiste em controlar a formação dos clusters de tal forma a particionar a imagem da maneira desejada. O controle aplicado à evolução do mapa deve ser tal a selecionar as características importantes, desprezar as insignificantes, e impedir a formação 
espontânea de clusters. O objetivo é fazer a rede de mapas acoplados, cuja entrada ou condição inicial é a imagem original, estabilizar na imagem segmentada.

Como a segmentação de imagens é um processo que visa separar partes que constituem uma imagem, é natural pensar que deve haver uma diminuição no acoplamento apenas nas fronteiras entre dois segmentos. Podemos então ser induzidos a deixar de pensar numa constante de acoplamento local $\varepsilon$ válida para todos os mapas para pensarmos numa matriz de acoplamento $\left(\varepsilon_{i_{j}}\right)$ cujos elementos representem a iteração ponderada de cada mapa com seus vizinhos.

Seguindo a heurística de que nas bordas dos segmentos o laplaciano transversal tende a ser maior, podemos elaborar uma relação empírica de forma que o acoplamento local diminua exponencialmente com o aumento do laplaciano. A equação (4.1) expressa essa idéia:

$$
\varepsilon_{i j}=e^{-\sigma \cdot\left|\Delta x_{i j}\right|}
$$

sendo $\Delta x_{i j}$ o laplaciano transversal no domínio discreto dado na equação (3.8) e $\sigma>0$ uma constante de decaimento. Podemos ter, por exemplo, além do acoplamento local $\varepsilon_{i j}$ com a vizinhança de Von Neumann de raio $1 g_{\mu}\left(x_{i, j}(t)\right)$, um acoplamento global $\alpha_{i, j}$ que também depende da posição $(i, j)$ do mapa $x_{i, j}(t)$ na rede bidimensional $m \times m$, conforme as equações (4.2) e (4.3) mostram:

$$
\begin{gathered}
x_{i, j}(t+1)=\left(1-\alpha_{i, j}\right)\left(\left(1-\varepsilon_{i, i}\right) f_{\mu}\left(x_{i, j}(t)\right)+\varepsilon_{i, i} g_{\mu}\left(x_{i, j}(t)\right)\right)+\alpha_{i, j} \sum_{k=1}^{m} \sum_{p=1}^{m} f_{\mu}\left(x_{k, p}(t)\right) \\
g_{\mu}\left(x_{i, j}(t)\right)=\frac{1}{4} \cdot\left(f _ { \mu } \left(x_{i-1, j}(t)+f_{\mu}\left(x_{i+1, j}(t)+f_{\mu}\left(x_{i, j-1}(t)+f_{\mu}\left(x_{i, j+1}(t)\right)\right.\right.\right.\right.
\end{gathered}
$$


A figura (4.4) mostra como essa idéia pode ser implementada de modo tal a decompor uma imagem em dois segmentos, um primeiro plano e um plano de fundo, que tendem a se tornarem desacoplados e dessincronizados.
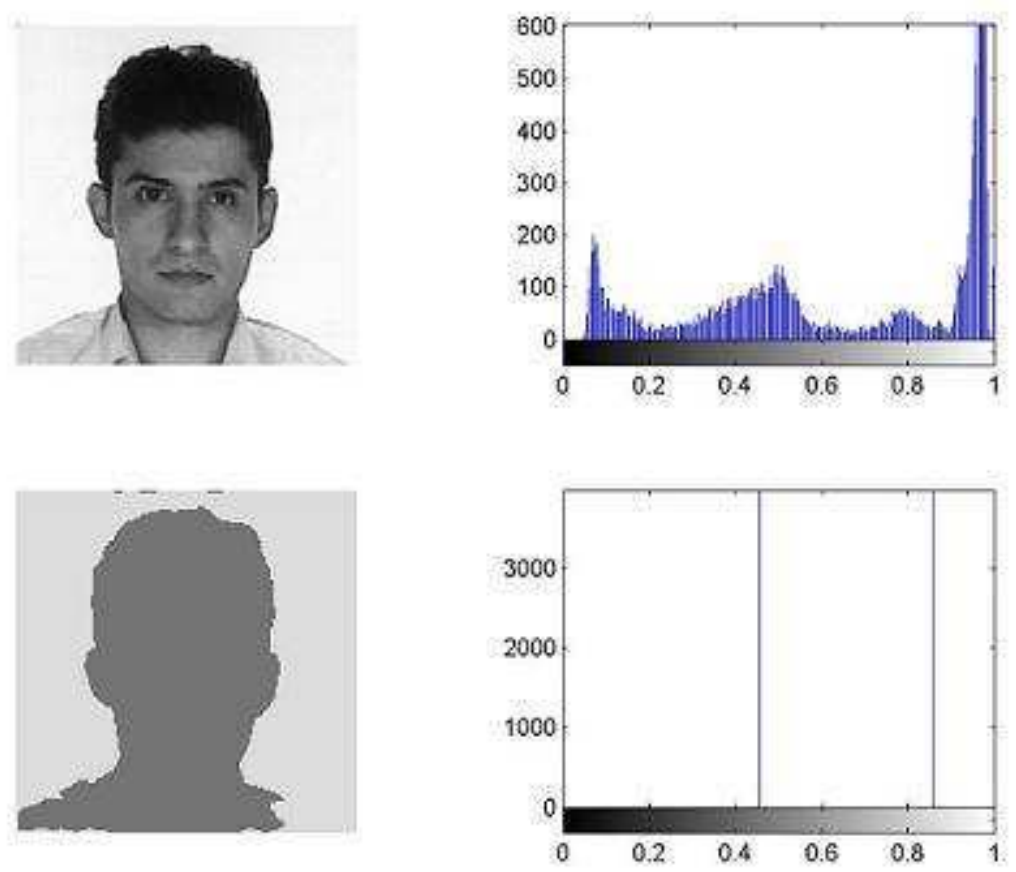

Figura 4.4 - Rede bidimensional de mapas acoplados com formação de 2 clusters com acoplamentos global e local de 0,1 e 0,8 respectivamente, e parâmetro de bifurcação 3,56. A imagem superior direita representa a entrada, e a inferior é a imagem segmentada após 30 iterações. À direita de ambas estão seus respectivos histogramas de níveis de cinza.

Inicialmente, o histograma de níveis de cinza apresenta quatro bandas espalhadas, que podem ser facilmente identificadas como correspondentes ao tom escuro do cabelo, em seguida a pele, a camisa, e, por fim, o tom claro do plano de fundo. Depois de inserir essa imagem, como estado inicial em uma rede de mapas, o acoplamento leva a uma tendência de aproximação de mapas vizinhos, sincronizando-os em um cluster. Já a dinâmica não-linear cria uma tendência de dispersão de valores de vizinhos que já possuem valores diferentes, o que cria a variação abrupta que corresponde à borda do cluster. 
Um outro exemplo é mostrado nas figuras (4.5) e (4.6).
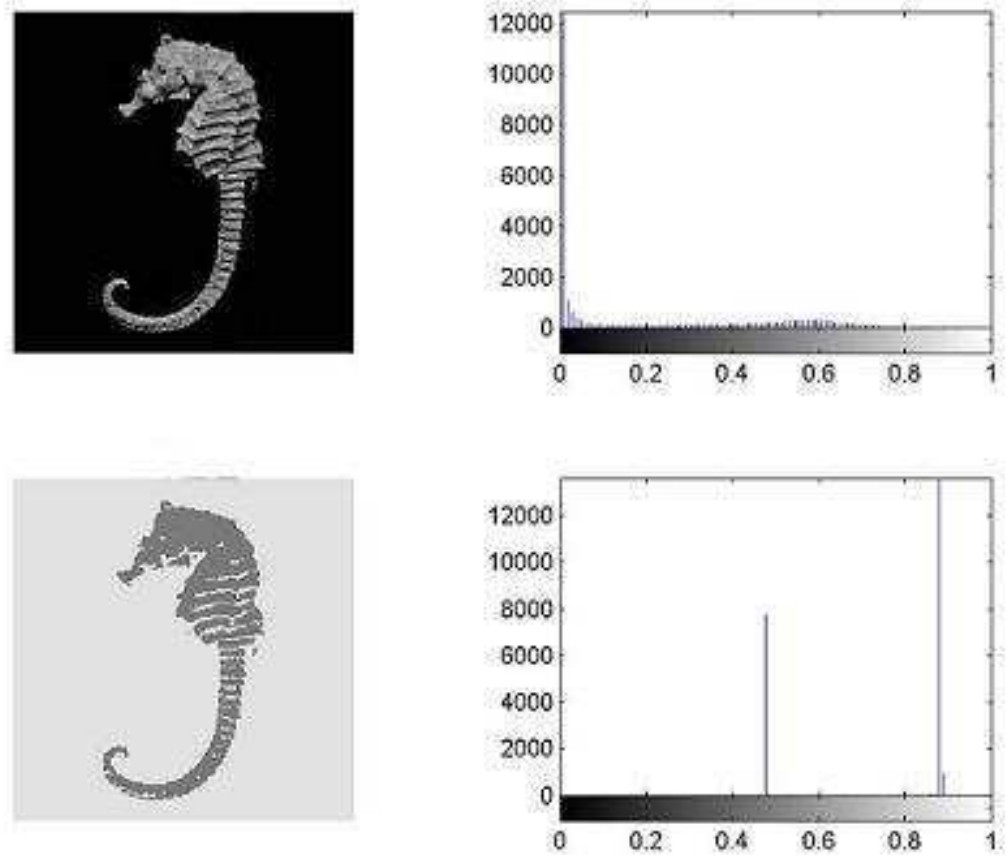

Figura 4.5 - Rede bidimensional de mapas acoplados com formação de 2 clusters com acoplamentos global e local de 0,1 e 0,8 respectivamente, e parâmetro de bifurcação 3,56. acompanhado de seu histograma de níveis de cinza. A imagem superior esquerda representa a imagem original de entrada em tons de cinza, e a inferior esquerda é a imagem segmentada após 30 iterações de mapas acoplados. À direita estão os seus respectivos histogramas de níveis de cinza ao lado de cada um.

O histograma inicialmente espalhado da figura (4.5) estabiliza-se num histograma com apenas dois tipos de valor, ou seja, dois clusters. Na figura (4.6) é mostrada apenas a figura correspondente à matriz de acoplamento local $\left(\varepsilon_{i_{j}}\right)$, que por si só já funciona como uma detecção do contorno da imagem.

Vale observar que claramente houve uma redução na entropia informacional após a segmentação, isto é, as imagens foram simplificadas. É nesse ponto em que reside a importância de se segmentar imagens: uma imagem mais simples é mais 
fácil de ser processada. O objetivo final da segmentação é obter uma forma de préprocessamento que torne a posterior análise mais simples. O problema reside em como escolher os parâmetros de controle de forma tal a selecionar apenas a informação relevante a uma determinada aplicação.

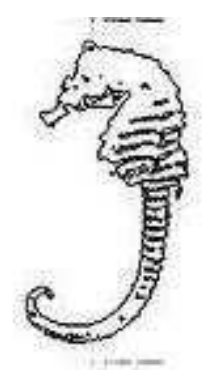

Figura 4.6 - Representação visual da matriz de acoplamento local $\left(\varepsilon_{i j}\right)$ da simulação mostrada na figura 4.4. O contorno da imagem, representado na cor preta, mostra que nesses pontos o acoplamento local estabiliza próximo de zero, separando o sincronismo do cluster que representa o cavalo-marinho do que representa o fundo da imagem.

Geralmente, melhores resultados são obtidos quando a entrada é reduzida por um fator de $10 \%$ do original. Isso acontece, possivelmente, porque valores iniciais baixos tendem a crescer lentamente no mapa logístico, aproximando-se de um crescimento exponencial. Dessa forma, asseguramos que os mapas não tenham seus valores dispersados de forma caótica apesar do acoplamento. Os mapas vizinhos com valores iniciais próximos devem crescer inicialmente no mesmo ritmo de modo a se aproximarem cada vez mais, até que façam parte de um mesmo cluster. Já mapas vizinhos com valores iniciais distantes devem crescer separadamente de forma a nunca entrarem em sincronia.

Para estudar formas de controle da segmentação utilizando dinâmica não-linear acoplada, foram feitas simulações de como o valor médio de alguns índices de dispersão são alterados pelos parâmetros de bifurcação e acoplamento utilizando um mapa unidimensional em anel, conforme a figura (4.6). O objetivo de tais simulações é determinar quais intervalos de $\varepsilon_{i j}$ e $\mu$ são convenientes. Medem-se entropia e variância, usando ora acoplamento global, ora acoplamento local com 
vizinhança de Von Neumann de raio 1. São apresentados as médias temporais de cada índice.

As figuras (4.6) e (4.7) mostram a variação da entropia informacional com os parâmetros de controle do mapa.

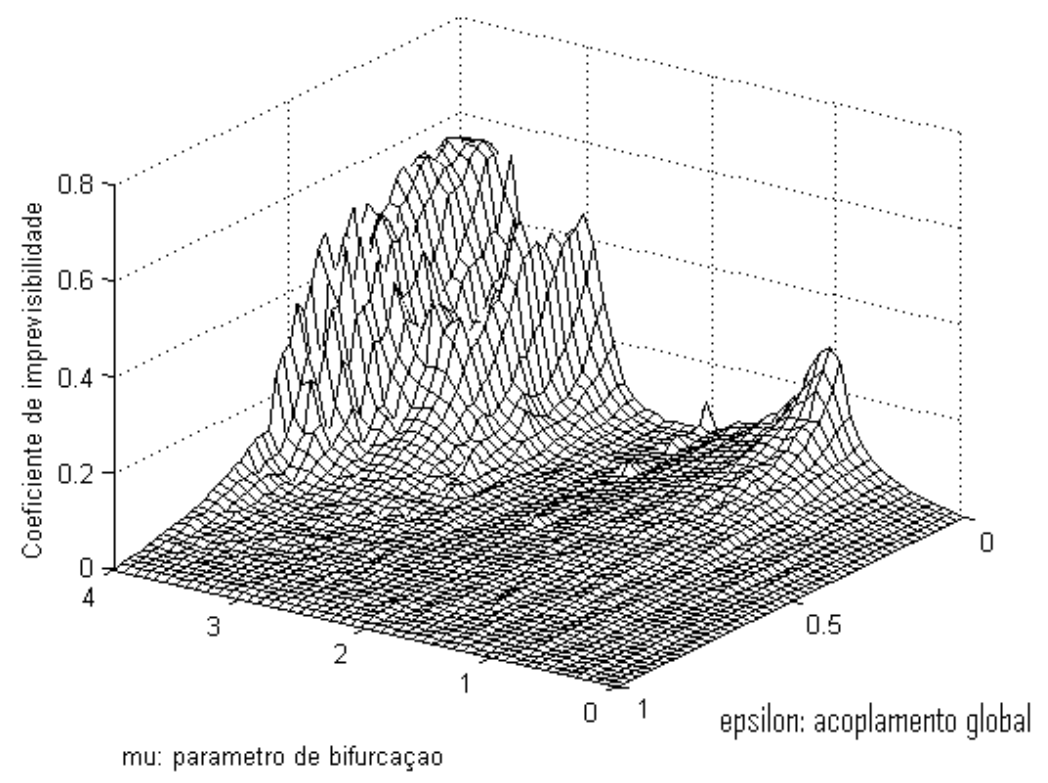

Figura 4.6 - Variação da entropia informacional (média de 30 iterações) com o parâmetro de bifurcação e o acoplamento global.

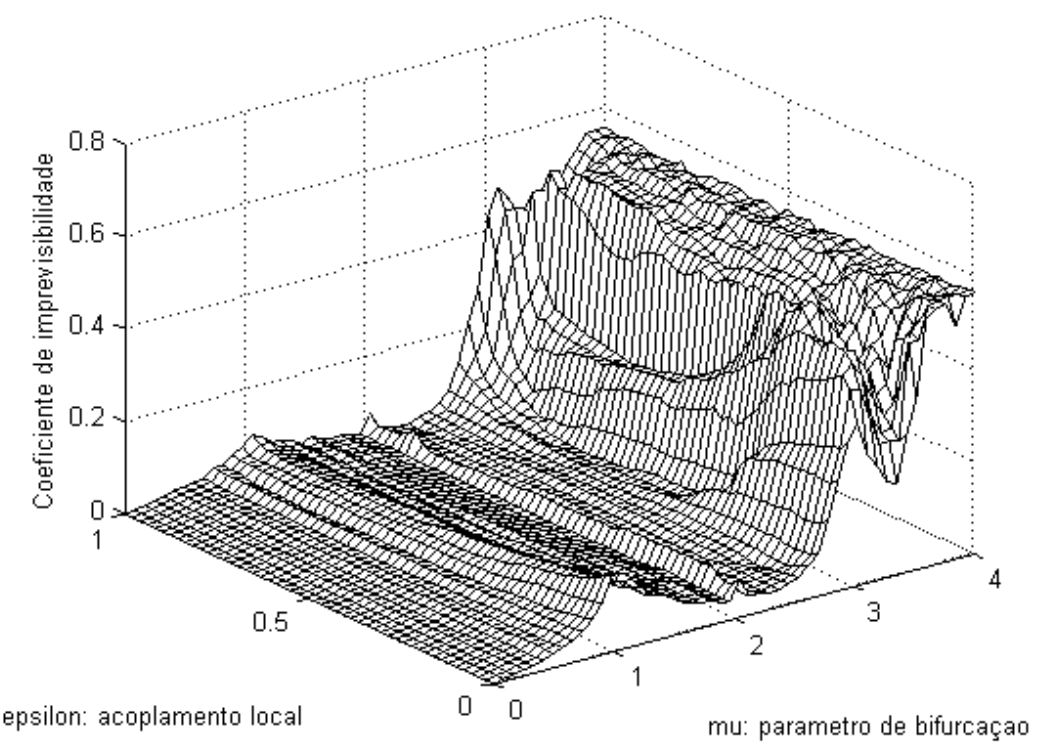

Figura 4.7 - Variação da entropia informacional (média de 30 iterações) com o parâmetro de bifurcação e o acoplamento local. 
A conclusão decorrente da visualização da figura (4.7) é que a entropia não varia consideravelmente com o acoplamento local $\varepsilon$ quando esse é um parâmetro concentrado. Isso nos fornece um possível indício de que um parâmetro local distribuído $\varepsilon_{i j}$ provavelmente é uma escolha mais acertada. O coeficiente de nãolinearidade, $\mu$, entretanto faz a entropia variar bastante, o que não invalida o seu uso como parâmetro concentrado de controle.

Embora a entropia informacional nos forneça uma medida da imprevisibilidade de uma fonte de sinal, o seu cálculo assume que a probabilidade de um mapa qualquer possuir determinado valor é independente dos valores de seus vizinhos. Porém, o acoplamento local cria uma relação de interdependência entre os valores dos vizinhos, o que pode levar a pensar na possibilidade de uso de probabilidades condicionais no cálculo da entropia.

Além disso, o cálculo da entropia também não leva em consideração a proximidade entre níveis distintos, mas apenas as suas probabilidades de ocorrência. Em outras palavras, a entropia não é uma função do espalhamento do histograma de níveis de cinza. Como uma alternativa à entropia, as figuras (4.8) e (4.9) analisam a variação um outro índice de desempenho em função dos parâmetros de controle: a variância.

É natural que nem a entropia, nem a variância variem muito com o acoplamento local como mostram as figuras (4.7) e (4.9), já que esse influi sobre menos mapas do que o acoplamento global. E também que, diante do acoplamento global, a imprevisibilidade só seja significativa para altos valores de $\mu$ e pequenos valores de $\varepsilon$, já que o primeiro coeficiente leva ao caos e o segundo a uma difusão. 


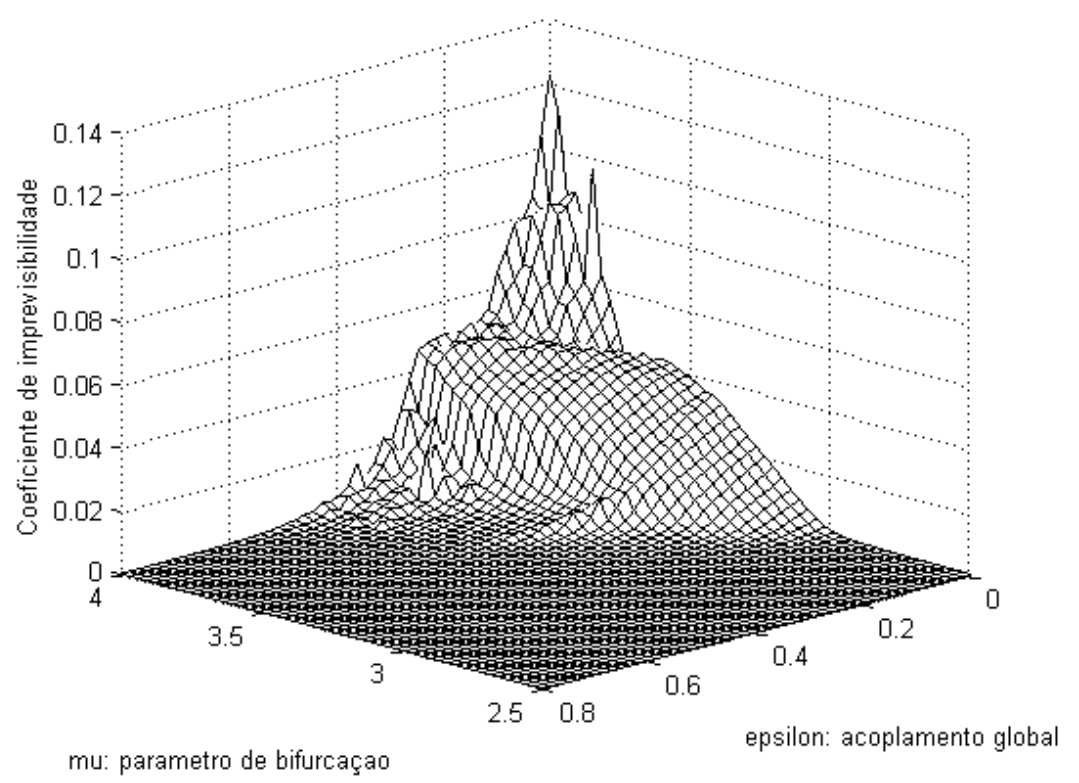

Figura 4.8 - Distribuição da variância (média de 30 iterações) com o parâmetro de bifurcação e o acoplamento global.

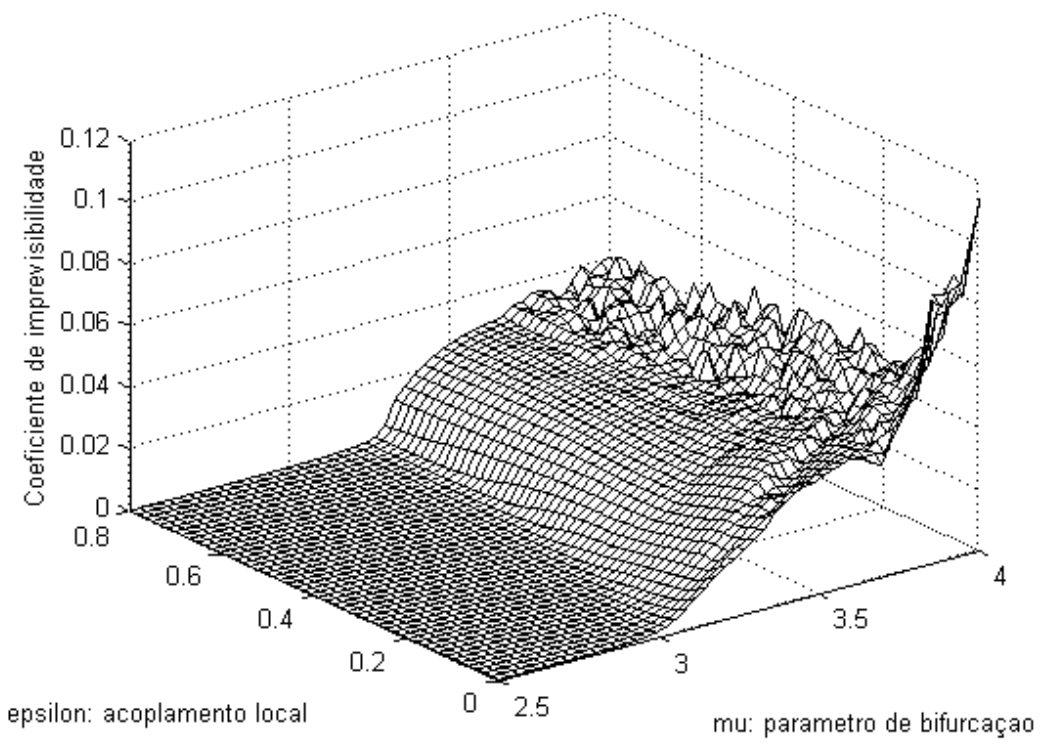

Figura 4.9 - Distribuição da variância (média de 30 iterações) com o parâmetro de bifurcação e o acoplamento local. 
As figuras (4.10) e (4.11) mostram uma composição de entropia com variância, para que dessa maneira seja possível medir o conteúdo informacional levando também em conta a proximidade entre níveis distintos. $\mathrm{O}$ índice usado foi o produto da entropia pela variância, o que pode representar uma medida de complexidade.

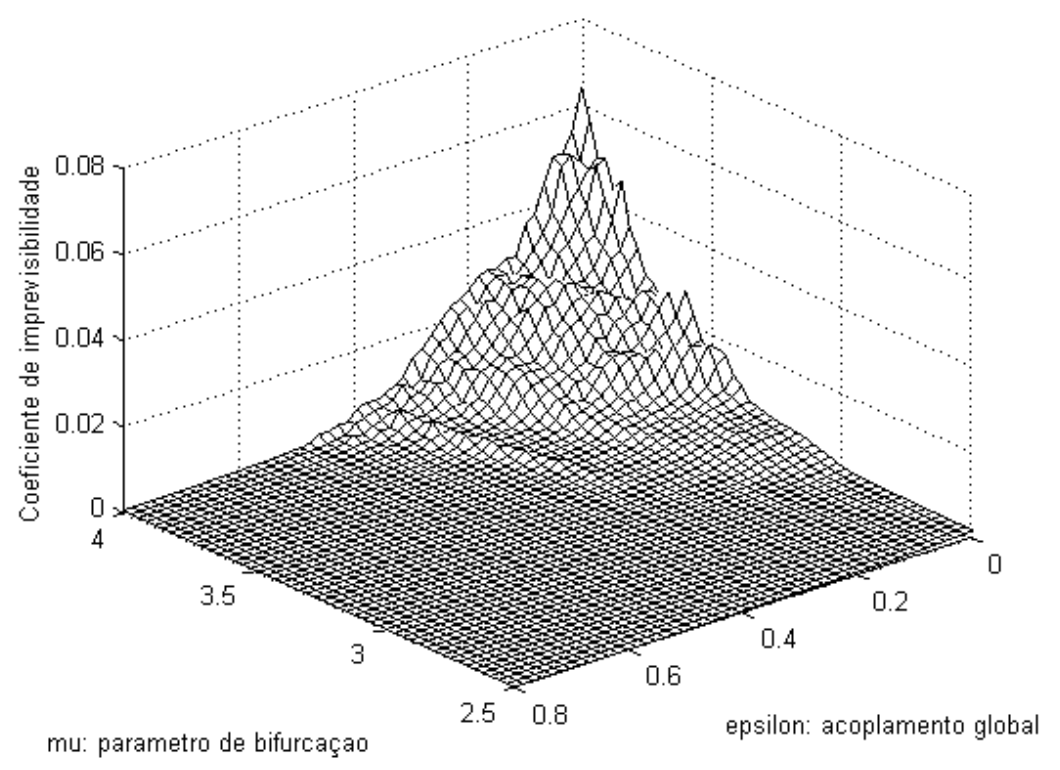

Figura 4.10 - Distribuição do produto da entropia pela variância (média de 30 iterações).

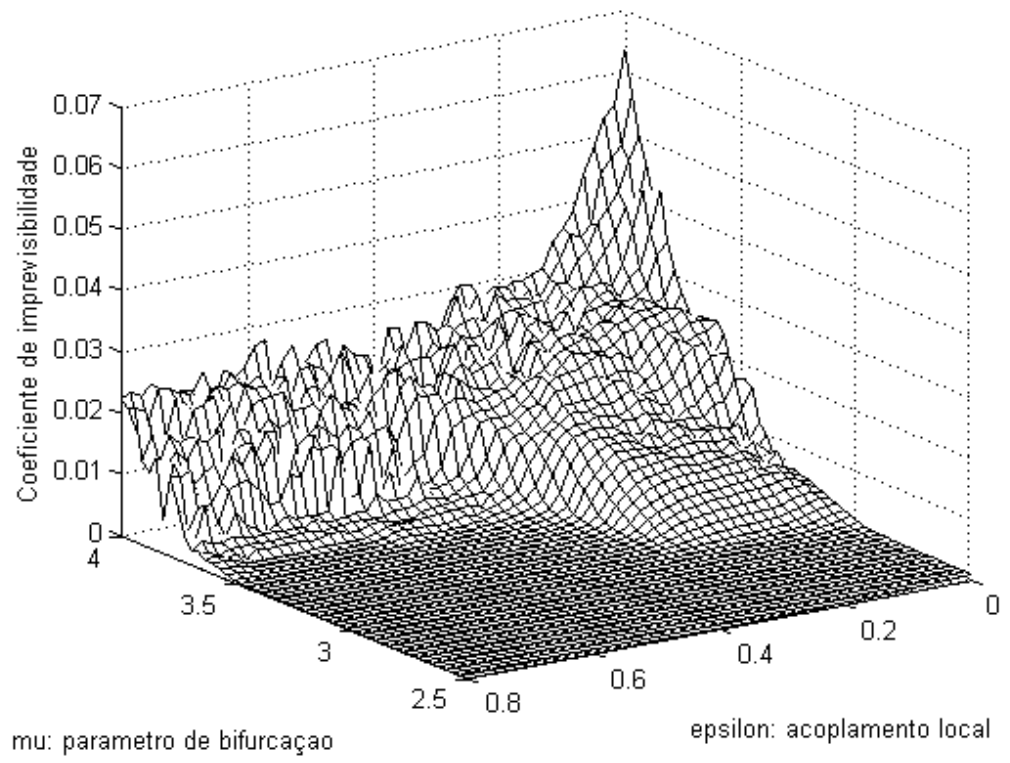

Figura 4.11 - Distribuição do produto da entropia pela variância (média de 30 iterações). 
Tais gráficos podem auxiliar na elaboração das leis de controle como explicado qualitativamente a seguir. Posteriormente, na seção 4.2, essas leis de controle são representadas por equações matemáticas.

Os mapas pertencentes a um dado cluster (que é candidato a tornar-se um segmento de imagem) possuem valores próximos. Para que esse cluster se mantenha, é necessário que se aumentem os valores de acoplamento local $\varepsilon_{i_{j}}$ em seu interior, o que leva a uma aproximação ainda maior dos valores dos mapas que formam esse cluster. Por outro lado, é necessário que se diminuam os valores de $\varepsilon_{i_{j}}$ em torno das bordas do cluster, o que aumenta a tendência de separação de mapas contíguos que estão de lados opostos da borda, levando à segmentação. Sabese que se está próximo de uma borda medindo-se o gradiente discreto: no interior do cluster, o valor do módulo do gradiente é menor do que na borda.

O parâmetro de não-linearidade $\mu$ é variado do seguinte modo: em regiões em que os mapas apresentam valores "muito" diferentes (o que é medido através do laplaciano discreto), deve-se aumentar $\mu$, a fim de que tais valores se distanciem ainda mais.

A segmentação surge do conflito entre a tendência de homogeneização provocada pelo acoplamento $\varepsilon_{i j}$ e a possibilidade de distanciamento dos valores dos mapas causada pela não-linearidade expressa pelo parâmetro $\mu$. Controlando-se essas duas grandezas, pode-se segmentar uma imagem.

As figuras (4.7), (4.9) e (4.11) confirmam que valores elevados de $\mu$ combinados com valores pequenos de $\varepsilon_{i j}$ tendem a aumentar a diversidade dos valores dos mapas, expressa pela entropia informacional e/ou variância. As figuras (4.6), (4.8) e (4.10) reforçam essa idéia, ou seja, valores elevados de $\mu$ e valores pequenos de acoplamento local $\alpha$ também levam a maior diversidade, mas de modo ainda mais acentuado. 
Portanto, todos os mapas de um cluster em processo de segmentação possuem um valor de $\varepsilon_{i j}$ muito próximo de um $\varepsilon$ característico daquele cluster. Para que esse cluster seja selecionado de forma correta, o par ordenado $(\varepsilon, \mu)$ deve estar inicialmente numa região lisa da superfície de alguma das figuras (4.6) a (4.11), para que esses valores possam ser variados (da maneira já descrita) de forma a se obterem resultados previsíveis.

Vale ainda ressaltar que a redução da entropia informacional de uma imagem devida à sua segmentação corresponde a uma heurística de segmentação conhecida como afinamento do histograma [Bow, 1992], conforme pode ser notado nas figuras (4.4) e (4.5). Essa técnica visa transformar a imagem de entrada em uma imagem com um menor número de níveis de cinza, ou seja, com poucos picos no seu histograma. O objetivo é descartar a informação irrelevante, que no caso são os valores muito próximos entre elementos vizinhos, que tendem a ser equalizados; e extrair a informação desejada, que são as linhas de contorno que separam elementos com uma elevada discrepância de valor.

\subsection{Modelo desenvolvido: heurísticas e resultados}

Alguns modelos de segmentação de imagens utilizam filtros de Gabor para realizar a segmentação por mapas acoplados [Ruiz-del-Solar, 1998; Nicolini e Prado 2002]. Tais filtros são constituídos de ondas planas senoidais combinadas com gaussianas bidimensionais [Leeuwen et al, 1997]. Aqui, optamos por uma abordagem mais simples, fazendo uso principalmente dos operadores de Sobel, introduzidos no capítulo 2, como uma das máscaras do processo de controle retroalimentado que conduz à segmentação.

A teoria da Gestalt, proveniente da Psicologia, também tem sido usada como heurística para extrair informação de imagens fotográficas [Assadi et al, 2001]. Essa teoria baseia-se em análises estruturais que regem a percepção humana das formas visando facilitar a compreensão das imagens e idéias. Para segmentar uma imagem 
por meio de mapas acoplados, usam-se os princípios da Gestalt conhecidos como similaridade, proximidade e boa-continuidade. É intuitivo que, num modelo que faça uso de mapas acoplados, os dois primeiros sejam decorrentes do acoplamento local; e que alguma manipulação sobre esse acoplamento deva ser realizada para controlar o processo de segmentação. O princípio da boa-continuidade é decorrente das bordas que os clusters tendem a formar, que tendem a ser contínuas. Há ainda um outro princípio conhecido como clausura, que é uma tendência das imagens interpretadas serem constituídas de regiões fechadas ou segmentos; esse princípio possui analogia com os próprios clusters presentes em uma rede de mapas acoplados. Outras duas leis da Gestalt, conhecidas como pregnância e experiência passada, seriam relativas, respectivamente, à interpretação da informação e ao reconhecimento de padrões, e não têm paralelo com o modelo aqui desenvolvido, já que exigiriam um grau maior de sofisticação.

Entretanto, seguir tais princípios à risca é um ato que pode significar algumas limitações para conseguir o resultado desejado. O princípio da clausura, por exemplo, possui certas restrições na sua gama de aplicações, já que a linha a ser detectada numa imagem do mundo real não é necessariamente fechada. Então, para que tal linha possa ser obtida, a perda de sincronismo entre os mapas que estão separados por ela deve ser grande o suficiente para haver detecção; porém, pequena o suficiente para que a linha não forme espontaneamente dois ou mais clusters. Haveria, assim, o aparecimento de uma informação que poderia ser interpretada erroneamente.

Outro problema consiste no fato de que mapas acoplados tendem a uma formação espontânea de clusters. Essa formação tende a descorrelacionar a imagem dinâmica, que é uma matriz de mapas acoplados, com a imagem original. Uma das maneiras encontradas para contornar ambos os problemas foi aumentar a tendência de sincronização de todos os mapas da rede por meio de um parâmetro escalar de acoplamento global a ser ajustado, contribuindo para uma sincronização mais rápida entre mapas com valores próximos. Outra maneira é ajustar uma matriz de acoplamento local fortalecendo os acoplamentos de vizinhos com valores próximos e enfraquecendo-os quando os valores estão mais distantes. O ajuste da matriz de 
acoplamento local é uma heurística que segue a lei de Hebb e seu controle é realizado com operadores de Sobel servindo como sensores.

Além disso, podemos tomar por base o fato de que o mapa logístico é um modelo de crescimento populacional que apresenta comportamento quase linear para valores iniciais próximos de zero. Desse modo, todos os elementos que constituem a matriz de entrada que representa a imagem original podem ser multiplicados por um fator diminutivo inicial $a_{0}$. Assim, o comportamento dinâmico qualitativamente mais próximo dos mapas nos instantes iniciais, por ser aproximadamente exponencial, faz com que todos cresçam inicialmente numa taxa próxima. Isso aumenta a sincronização em um momento em que os mapas ainda estão bastante correlacionados com a imagem original de entrada.

Vale notar que um princípio seguido nesse trabalho é o de que todo o controle deve ser feito para que as formas presentes na matriz de mapas acoplados não percam a sua correlação com a imagem original, ou pelo menos de que essa perda de correlação seja a mínima possível. Caso contrário, a informação relevante a ser extraída na segmentação pode ser destruída, ou informações errôneas podem surgir espontaneamente devido à natureza caótica de sua dinâmica, levando uma etapa de processamento posterior à segmentação a erros de interpretação.

O algoritmo dispõe de constantes que são ajustadas conforme as características da imagem original e do grau de precisão desejado na segmentação. A seguir, mostram-se listas das constantes envolvidas no problema. 
$a_{0} \quad$ Valor máximo inicial

$\mu_{\text {min }} \quad$ Valor mínimo do parâmetro de não-linearidade

$\mu_{\max } \quad$ Valor máximo do parâmetro de não-linearidade

$\tau$ Taxa de decaimento da influência da imagem original como entrada forçada

$T_{1}, T_{2}$ Períodos de reinserção da imagem original

$\sigma \quad$ Constante de ajuste sigmoidal do acoplamento local

$\alpha \quad$ Acoplamento global

$\varepsilon_{\max } \quad$ Acoplamento local máximo

$h \quad$ Coeficiente de histerese

$\sigma_{a} \quad$ Coeficiente sigmoidal da matriz de amplitudes

$\theta_{a} \quad$ Deslocamento sigmoidal da matriz de amplitudes

$\left(x_{i j}\right)_{0} \quad$ Matriz quadrada $(m \times m)$ correspondente à figura original em tons de cinza

Tabela 4.1 - Constantes do algoritmo iterativo de segmentação.

$\left(x_{i j}(t)\right)$ Matriz quadrada $(m \times m)$ dos mapas logísticos acoplados em tons de cinza no intervalo [l $\left.\begin{array}{ll}0 & 1\end{array}\right]$, sendo que $x_{i j} \in \mathfrak{R}$

$\left(\varepsilon_{i j}(t)\right)$ Matriz quadrada $(m \times m)$ dos acoplamentos locais

$\left(\varepsilon_{(h) i j}(t)\right)$ Matriz quadrada $(m \times m)$ dos acoplamentos locais após tratamento de histerese

Tabela 4.2 - Matrizes do algoritmo iterativo de segmentação.

$f_{\mu}(\cdot) \quad$ Função logística

$\operatorname{Grad}(\cdot) \quad$ Módulo do operador gradiente

$\delta_{i j}(\cdot) \quad$ Função matricial do laplaciano discreto

Tabela 4.3 - Funções do algoritmo iterativo de segmentação. 
Antes do processo de iteração, obtemos os valores iniciais de $x_{i j}$ :

$$
\left(x_{i j}(0)\right)=\left(1-\left(x_{i j}\right)_{0}\right) \cdot a_{0}
$$

A equação (4.4) baseia-se na heurística anteriormente explicada de manter os valores iniciais de $\left(x_{i j}(t)\right)$ mais baixos, para que a característica aproximadamente linear de crescimento exponencial contribua com uma sincronização mais forte entre elementos vizinhos com valores próximos.

A dinâmica do modelo aqui desenvolvido segue as seguintes equações empíricas:

$$
\mu(t)=\frac{\left(\delta_{i j}\left(x_{i j}(t)\right)+1\right)}{2} \cdot\left(\mu_{\max }-\mu_{\min }\right)+\mu_{\min }
$$

A equação (4.5) se explica pela heurística de que o valor do parâmetro de nãolinearidade deve ser maior quanto maior for o laplaciano. Isto é, regiões com variações mais bruscas devem possuir uma maior sensibilidade às condições iniciais para contribuir na dessincronização de elementos vizinhos nas fronteiras a serem segmentadas.

$$
\varepsilon_{i j}(t)=\varepsilon_{\max } \cdot \frac{2}{1+e^{\sigma \cdot G r a d}\left(x_{i j}(t)\right)}
$$

A equação (4.6) toma por base o fato de o acoplamento local deve decrescer com o módulo do gradiente, que indica a existência de uma fronteira de variação brusca de nível de cinza. A função Grad é o módulo do gradiente discreto, e equivale a $\operatorname{Grad}()=.\sqrt{G x(\cdot)^{2}+G y(\cdot)^{2}}$, sendo que $G x($.$) e G y($.$) são as componentes horizontal e$ vertical do gradiente. Vale observar que essas componentes de gradiente discreto são os operadores de Sobel mostrados na figura (2.17). Neste trabalho, sempre que possível, optamos por funções sigmoidais para expressar a dinâmica iterativa, já que desejamos simular um modelo neural por meio de uma dinâmica não-linear. E, 
também pelo fato de funções dinâmicas sigmoidais possuírem uma variação suave, o que facilita o controle do processo.

Conforme explicado, a dinâmica não-linear dos mapas tende à formação arbitrária de clusters, o que é prejudicial para uma segmentação adequada. Portanto, faz-se necessário inserir alguma tendência de estabilização de algum tipo para dificultar que o comportamento caótico leve a uma formação de fronteira de clusters em pontos em que não existem variações bruscas na imagem original; bem como para manter um acoplamento forte nas regiões em que uma fronteira foi previamente detectada. Essa tendência de estabilização que contribui para manter valores de acoplamento local, impedindo variações arbitrárias, é obtida por meio de uma relação de histerese. A equação (4.7) expressa essa relação, subtraindo a derivada temporal discreta do acoplamento multiplicada por um fator de histerese. Como a derivada é um indicador do crescimento no tempo, a sua subtração faz com que a sigmóide tenha valores mais baixos no sentido do crescimento da abscissa e valores mais altos no sentido do decrescimento da abscissa, conforme a figura (4.12).

$$
\varepsilon_{(h) i j}(t)=\varepsilon_{i j}(t)-h \cdot\left(\varepsilon_{i j}(t)-\varepsilon_{i j}(t-1)\right)
$$

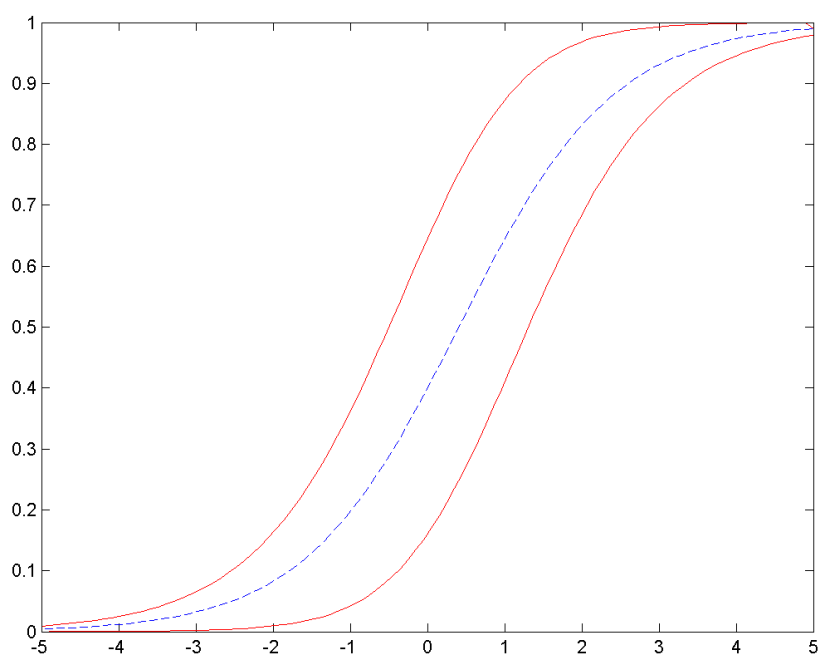

Figura 4.12 - Curva de histerese obtida fazendo uso de uma fórmula recursiva similar à da equação (4.7) aplicada a uma função sigmoidal como a da equação (4.6). A curva do meio representa a função sigmoidal com fator de histerese nulo. 
A dinâmica logística não-linear e acoplada é expressa nas equações (4.9), (4.10) e (4.11):

$$
\begin{gathered}
x_{(n)_{i, j}}(t)=(1-\alpha) \cdot\left[\left(1-\varepsilon_{(h) i j}\right) \cdot f_{\mu}\left(x_{i, j}(t)\right)+\frac{\varepsilon_{(h) i j}}{4} \cdot f_{\mu}\left(x_{i-1, j}(t)+x_{i+1, j}(t)+x_{i, j-1}(t)+x_{i, j+1}(t)\right)\right] \\
\quad+\frac{\alpha}{m^{2}} \cdot \sum_{i=1}^{m} \sum_{j=1}^{m} f_{\mu}\left(x_{i, j}(t)\right) \\
x_{i, j}(t+1)=\left(1-0.7 \cdot e^{-\tau \cdot\left(\bmod \left(t, T_{1}\right)\right)}\right) \cdot x_{(n)_{i, j}}(t)+0.7 \cdot e^{\left.-\tau \cdot \bmod \left(t, T_{1}\right)\right)} \cdot\left(1-\left(x_{i j}\right)\right) \cdot a_{0}
\end{gathered}
$$

Enquanto a equação (4.9) é a rede de mapas acoplados em si, representando, portanto, uma resposta natural do sistema, a equação (4.10) representa a influência da entrada forçada que decai e é re-inserida periodicamente. A função $\bmod \left(t, T_{1}\right)$ é o resto da divisão do tempo discreto t pelo período $T_{1}$ em que a imagem original é inserida na rede. Esse foi um meio encontrado de impedir que a evolução arbitrária dos clusters faça com que a rede de mapas acoplados perca a relação com a imagem original; ao mesmo tempo em que a decadência da influência da entrada forçada no tempo permite a evolução da rede de modo que a equação (4.9) atue como um acentuador de contraste.

Para diminuir ainda mais a perda de correlação com a imagem original, um segundo termo de atribuição é feito a cada $T_{2}$ ciclos de iteração. Inserimos a imagem original com uma ponderação fraca, da ordem de $10 \%$, conforme mostrado na equação (4.11):

$$
x_{i, j}(t+1)=0.9 \cdot x_{i, j}(t+1)+0.1 \cdot\left(x_{i j}\right)_{0}
$$

Enfim, para obter uma segmentação desejada a partir da matriz de acoplamento local, existe o problema de seus valores mudarem com o tempo, existindo, portanto, a possibilidade de que detalhes importantes sejam perdidos. Além disso, a matriz de acoplamento local expressa valores contínuos em seus elementos: bordas de maior contraste apresentarão valores maiores do que bordas de menor contraste. Uma 
maneira de lidar com essa situação seria impor simplesmente uma função limiar à saída usando a matriz de acoplamento local como entrada. Porém, existem valores relevantes ao acoplamento, apesar de baixos; e valores altos para o acoplamento em detalhes irrelevantes como uma ou outra fraca formação espontânea de clusters. Contornamos esse problema usando do fato de os valores serem dinâmicos e, graças ao algoritmo utilizado, a variação dos valores é mais forte nas bordas de contraste, que é justamente onde está a informação a ser extraída para obtermos a segmentação da imagem.

Sendo assim, os valores máximos e mínimos dos elementos da matriz de acoplamento local são armazenados em duas matrizes. A diferença dessas duas matrizes representa a amplitude da variação no decorrer do tempo. Pontos onde essa amplitude é maior provavelmente são pontos em que existe uma borda relevante para o processo de segmentação. Naturalmente, uma função limiar deve ser empregada para diferenciar os pontos onde a amplitude é forte o suficiente para ser interpretada como uma borda dos pontos em que ela é fraca o suficiente para não representar informação válida. Essa função limiar pode ser uma função sigmoidal de variação brusca e apresentar um deslocamento a ser ajustado, conforme a equação (4.12):

$$
A_{i j}(t)=\frac{1}{1+e^{\sigma_{a} \cdot\left((\operatorname{Max}-\operatorname{Min})-\theta_{a}\right)}}
$$

sendo que:

$$
\begin{aligned}
& \text { Max }=\max _{\theta \leq t} \varepsilon_{(h) i j}(\theta) \\
& \text { Min }=\min _{\theta \leq t} \varepsilon_{(h) i j}(\theta)
\end{aligned}
$$

Para evitar o aparecimento de ruído na matriz de amplitudes, os procedimentos descritos pelas equações (4.12) e (4.13) só são realizados após determinada iteração. No nosso trabalho, essa iteração é $\mathrm{t}=10$. 
Feito isso, o algoritmo passa para a iteração seguinte, reiniciando o ciclo na equação (4.5).

A figura (4.13) mostra uma visualização das principais matrizes do algoritmo iterativo feita no software Matlab. Uma equalização de histograma (maximização do contraste) foi feita para exibir a matriz de amplitudes, na qual a segmentação final é obtida:

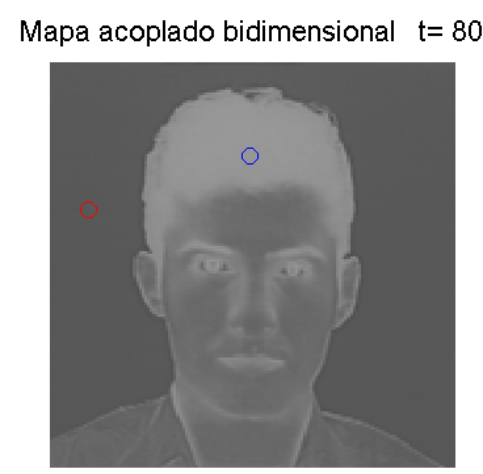

(a)

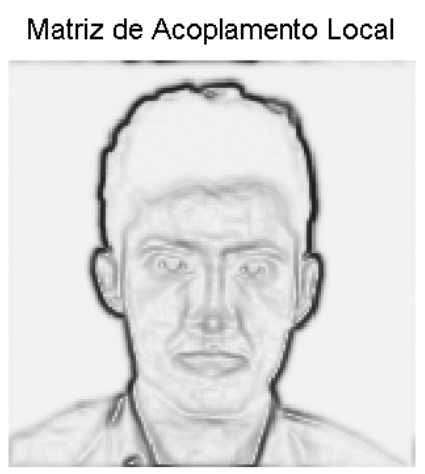

(c)

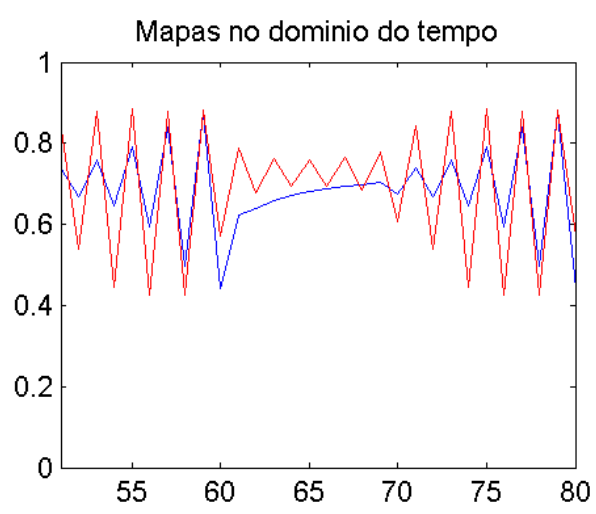

(b)

Limiar da Amplitude do acoplamento local

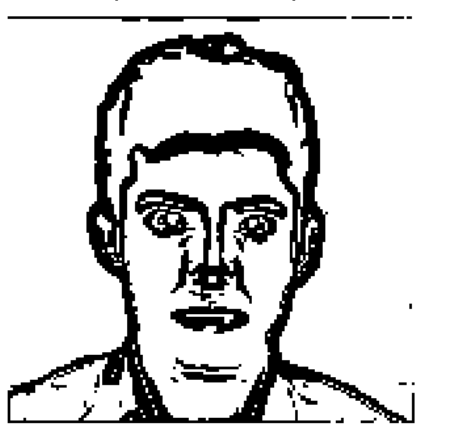

(d)

Figura 4.13 - Visualização do processo de segmentação da figura (4.4) após 80 iterações. Valores dos parâmetros: $a_{0}=0,8 ; \mu_{\min }=$ 3,$5 ; \mu_{\max }=3,7 ; \tau=0,135 ; T_{1}=20 ; T_{2}=10 ; \sigma=20 ; \alpha=0,035$; $\varepsilon_{\text {max }}=0,35 ; h=0,8 ; \sigma_{a}=5 ; \theta_{a}=4,8$.

A figura (4.13a) é a matriz associada à rede de mapas acoplados $x_{i, j}(t)$ em tons de cinza. Essa matriz deve ter seus valores controlados para que o processo de clustering contribua no aumento de contraste que leva à segmentação, sem conduzir o sistema a uma formação espontânea de clusters. A figura (4.13b) mostra a 
evolução de dois elementos da rede no tempo, destacados na figura (4.13a) por pequenas circunferências.

A figura (4.13c) reflete os valores da matriz de acoplamento local $\varepsilon_{i j}$ em tons de cinza. Os níveis mais claros representam um acoplamento local mais forte, enquanto os mais escuros representam um acoplamento local mais fraco. Em regiões nas quais há uma borda que, na imagem original, apresenta um contraste mais acentuado, aparece uma linha de contorno mais escura na matriz $\varepsilon_{i_{j}}$. No caso da figura (4.13c), a linha de maior contraste é a que separa a cabeça do plano de fundo. A matriz $\varepsilon_{i j}$, por ser formada de variáveis contínuas, ainda não é apropriada para visualização da segmentação. Isto é, seria mais interessante que a segmentação fosse expressa por uma matriz formada por variáveis binárias: por exemplo, branco para fundo e preto os contornos. Por isso, fizemos uso da amplitude de variação dos valores de $\varepsilon_{i j}$, armazenados na matriz de amplitudes (ver expressão (4.12)). Essa matriz é exibida na figura (4.13d) e ela é o resultado final da segmentação.

A figura (4.14) mostra como se dá o processo de evolução da matriz de amplitudes. Observe que aparenta tender assintoticamente a uma determinada figura segmentada. Para a maioria das figuras testadas, após 50 iterações, detalhes de contorno pouco significativos vão surgindo. Após 80 iterações praticamente nenhum novo detalhe é encontrado, e a segmentação se estabiliza.

As escolhas de $\mu_{\min }=3,5 ; \mu_{\max }=3,7$ e $\varepsilon_{\max }=0,35$ baseiam-se no fato de que a entropia informacional para esses valores apresenta inclinação elevada e superfície suave, como mostrado na figura (4.7). 


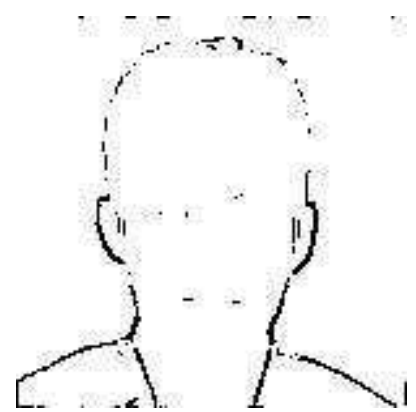

$\mathrm{t}=15$

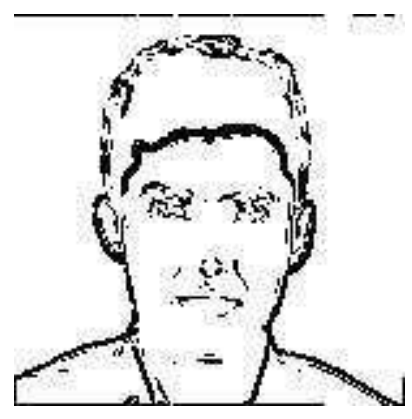

$\mathrm{t}=23$

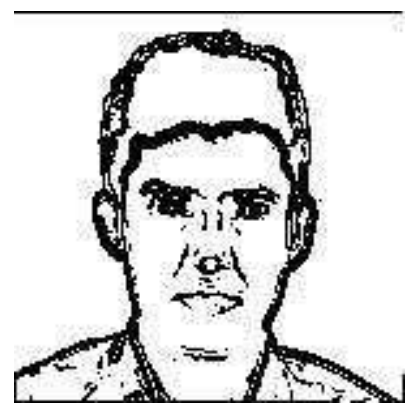

$\mathrm{t}=40$

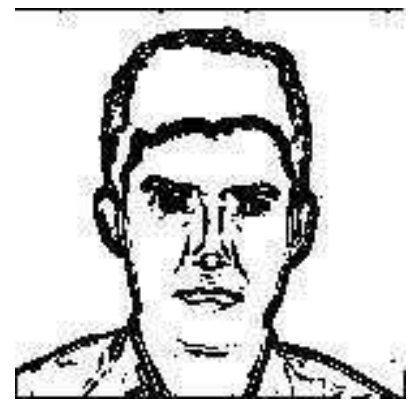

$\mathrm{t}=150$

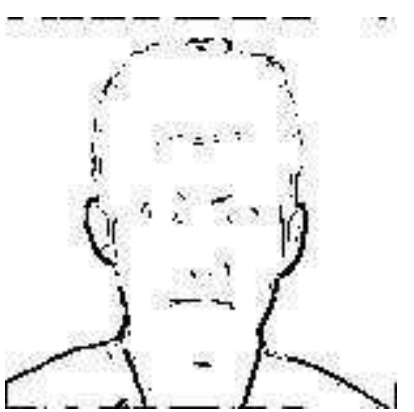

$\mathrm{t}=16$

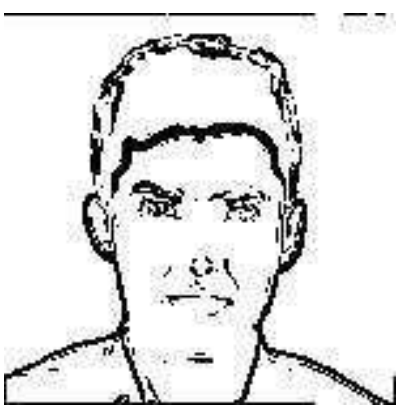

$\mathrm{t}=25$

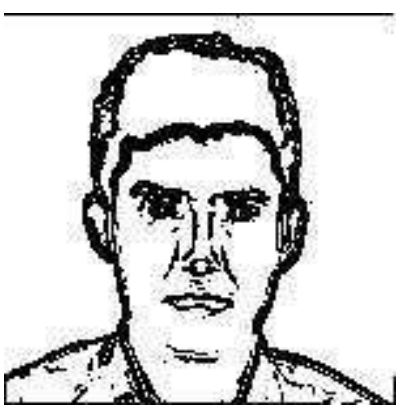

$\mathrm{t}=50$

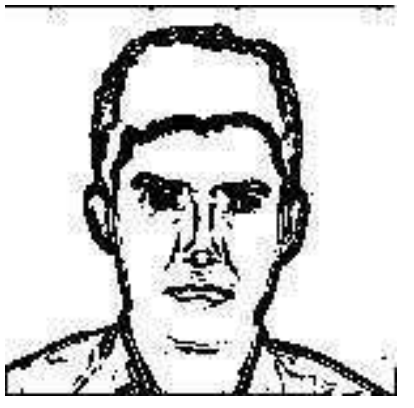

$\mathrm{t}=1000$

Figura 4.14 - Evolução temporal da matriz das amplitudes para $a_{0}=0,9$;

$$
\mu_{\text {min }}=3,5 ; \quad \mu_{\text {max }}=3,7 ; \tau=0,135 ; T_{1}=20 ; T_{2}=10 ; \sigma=20 ;
$$$$
\alpha=0,05 ; \varepsilon_{\max }=0,25 ; h=0,9 ; \sigma_{a}=5 ; \theta_{a}=3,8 \text {. }
$$ 


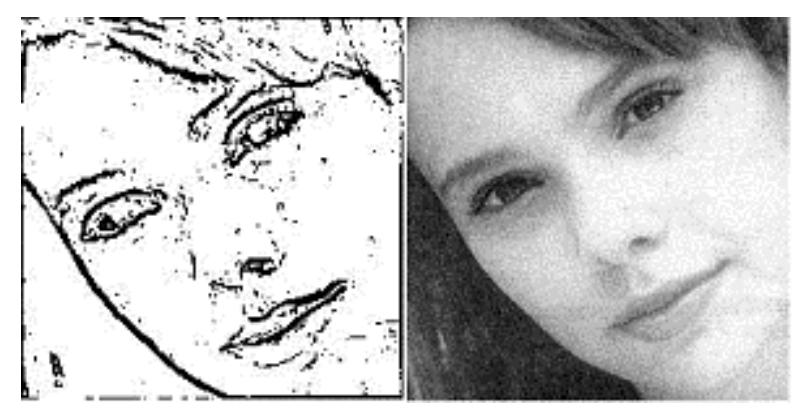

(a)

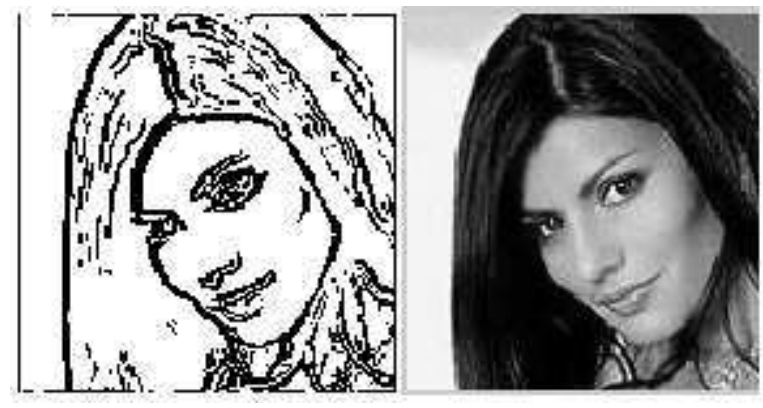

(b)

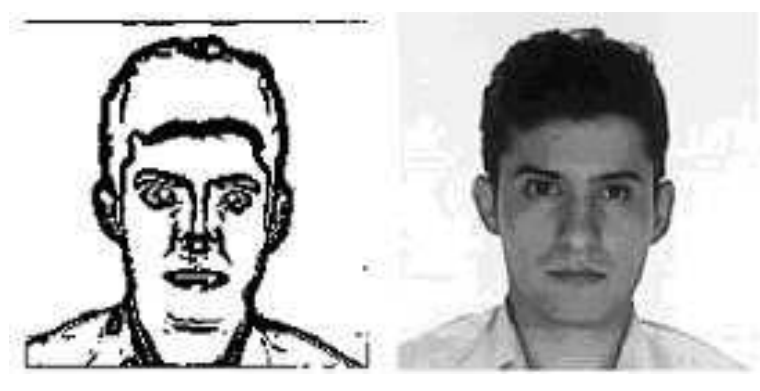

(c)

Figura 4.15 - Comparação entre algumas imagens segmentadas e suas originais.

O sistema de controle de segmentação desenvolvido possui limitações no que concerne à resolução da imagem original. Uma imagem granulada, como a da figura (4.15a), tende a uma formação de pontos isolados em regiões em que uma segmentação ideal consideraria como sendo uniforme. Diminuindo a sensibilidade para esse tipo de ruído, acaba-se também diminuindo a sensibilidade para a detecção de contornos relevantes. Na figura (4.15b), leves degrades que acompanham o penteado são melhores detectados do que o contorno da íris dos olhos. A figura 
(4.15c) apresenta uma segmentação que extrai detalhes relevantes do contorno relativamente bem em comparação com as figuras anteriores. Isso talvez resulte do fato de que mais combinações de valores de parâmetros tenham sido testadas nesta figura (na verdade, o sistema de extração de contorno foi desenvolvido tendo como referência a figura $(4.15 c))$.

Para imagens que possuem contornos bem definidos, como peças ou máquinas, como é o caso da figura (4.16), o nosso esquema de segmentação costuma apresentar resultados de melhor qualidade.

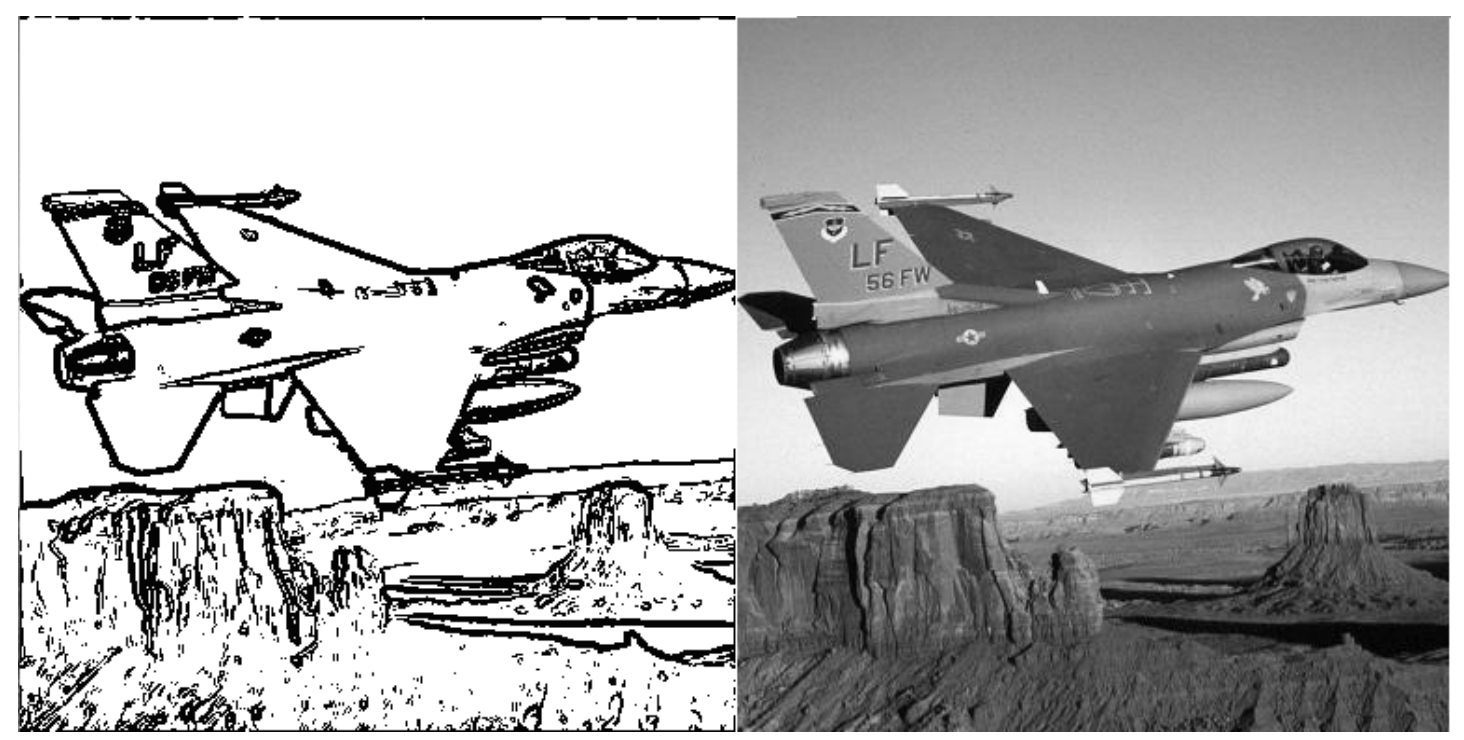

(a)

(b)

Figura 4.16 - (a) Figura segmentada com 80 iterações para $a_{0}=0,8$; $\mu_{\text {min }}=3,5 ; \quad \mu_{\max }=3,7 ; \tau=0,135 ; T_{1}=20 ; T_{2}=10 ; \sigma=20$; $\alpha=0,045 ; \quad \varepsilon_{\max }=0,45 ; \quad h=0,8 ; \quad \sigma_{a}=3,5 ; \quad \theta_{a}=4,8$. (b) Imagem original em tons de cinza. 


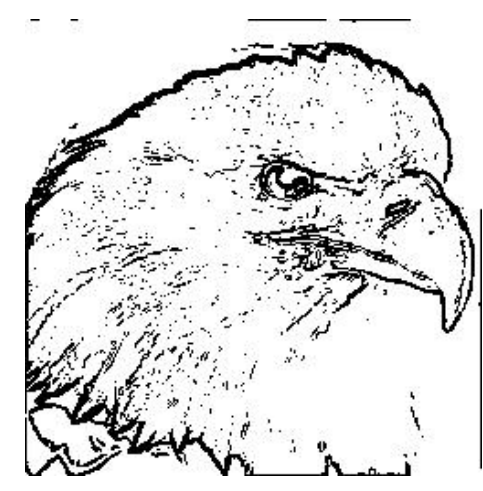

(a)

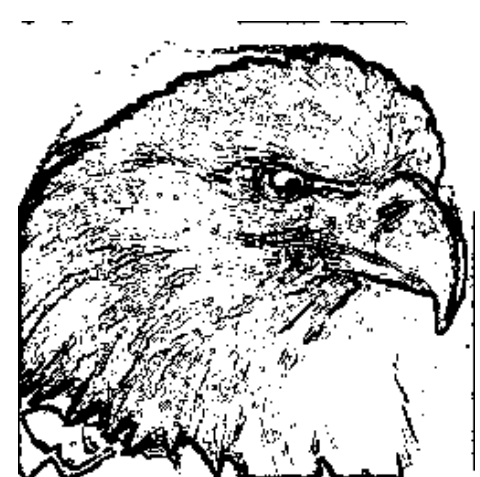

(b)

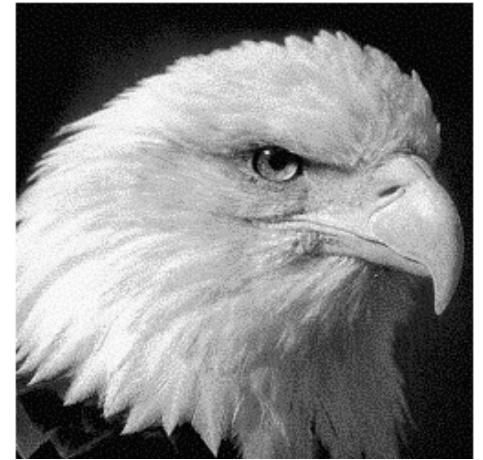

(c)

Figura 4.16 - (a), (b) Figura segmentada com 80 iterações para $a_{0}=0,8$; $\mu_{\min }=3,5 ; \quad \mu_{\max }=3,7 ; \tau=0,135 ; T_{1}=20 ; T_{2}=10 ; \quad \sigma=20 ;$ $\alpha=0,045 ; \varepsilon_{\max }=0,45 ; h=0,8 ; \sigma_{a}=3,5 ;$ sendo $\theta_{a}=5$ para (a) e $\theta_{a}=4,8$ para (b). Imagem original em tons de cinza (c).

As figuras (4.16a) e (4.16b) apresentam apenas um parâmetro com valor ligeiramente diferente, a saber, o deslocamento da curva sigmoidal $\theta_{a}$ (ver expressão (4.12)). Um menor valor de $\theta_{a}$ faz com que mais detalhes sejam capturados, inclusive detalhes irrelevantes que poderiam ser considerados como ruído. Isso acontece por causa do aumento da sensibilidade na detecção de variações de descontinuidades quando existe um $\theta_{a}$ menor. A figura (4.16b), por ser resultado de um processo de segmentação $\operatorname{com} \theta_{a}$ maior, possui contornos mais irrelevantes do que os presentes na figura (4.16a).

A figura (4.17) mostra o que alterações no coeficiente de histerese $h$ podem provocar (ver expressão (4.7)). Em (4.17c), o coeficiente $h$ é mais alto, diminuindo o efeito de retenção provocado pela histerese. Quanto maior $h$, mais próximas as curvas crescente e decrescente estão uma da outra, fazendo com que o efeito da histerese seja menor (ver figura (4.12)). Devido à menor sensibilidade para retenção, a figura (4.17c) possui menos contornos do que (4.17b) e (4.17d). Já a figura (4.17d) está, por sua vez, associada a um menor valor do limiar $\theta_{a}$, possuindo, portanto, uma maior sensibilidade a contornos de bordas de nível de cinza. 


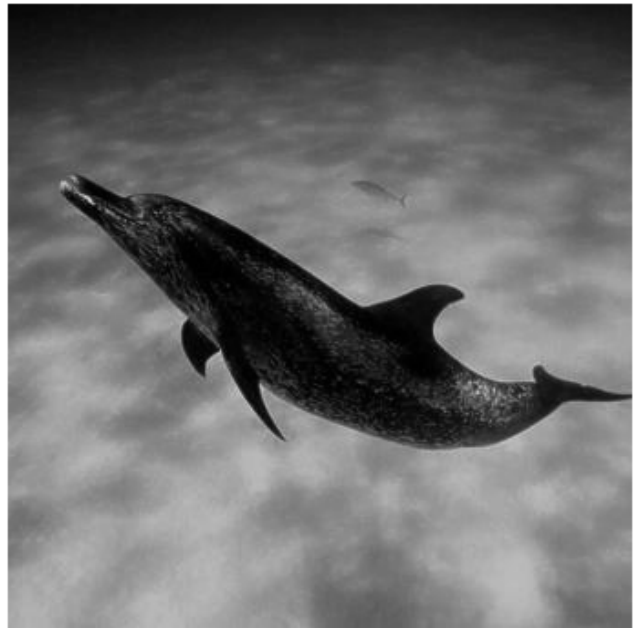

(a)

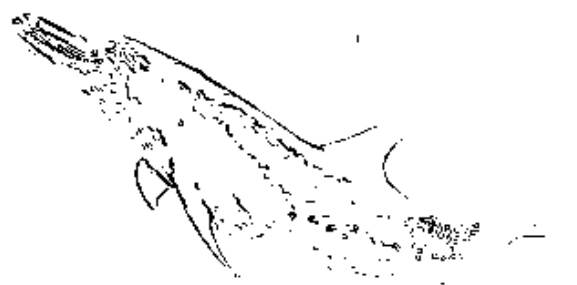

(c)

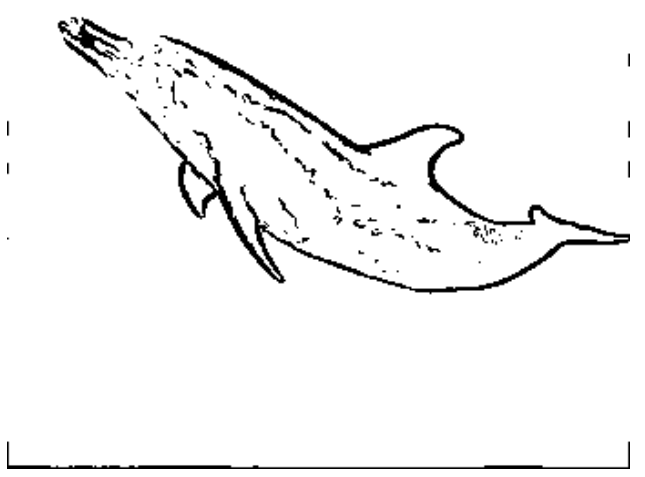

(b)

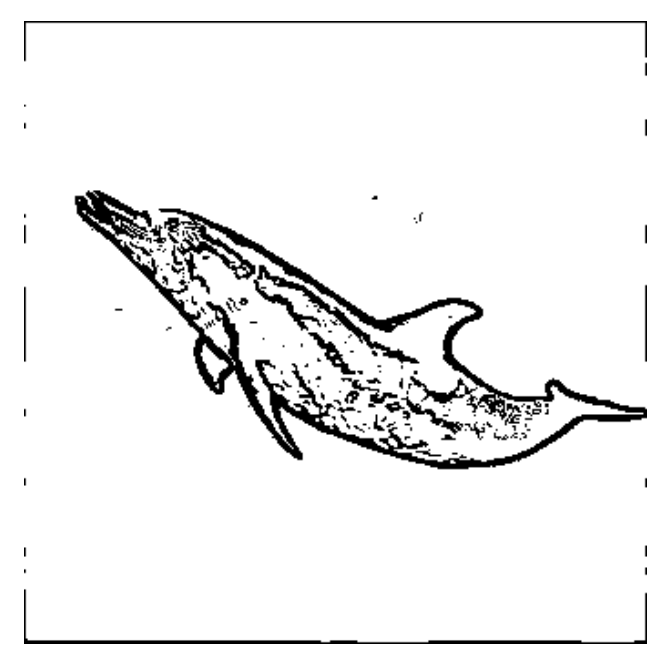

(d)

Figura 4.17 - (a) Imagem original em tons de cinza. (b), (c), (d) Figuras segmentadas com 80 iterações para $a_{0}=0,8 ; \mu_{\min }=3,5 ; \mu_{\max }=$ 3,$7 ; \tau=0,135 ; T_{1}=20 ; T_{2}=10 ; \sigma=20 ; \alpha=0,045 ; \varepsilon_{\max }=0,45 ;$ $\sigma_{a}=3,5$. Para (b) e (d) $h=0,8$; para (c) $h=0,9$. Para (b) e (c) $\theta_{a}=4,9 ;$ para (d) $\theta_{a}=4,8$.

Enfim, as escolhas de parâmetros aqui realizadas podem não ser as ótimas; mas, por inspeção visual, percebe-se que elas fornecem resultados satisfatórios. Encontrar, analiticamente, a combinação ótima de valores de parâmetros e desenvolver um método para avaliar se a imagem original foi satisfatoriamente segmentada são desafios futuros que pretendemos encarar. 


\section{CONSIDERAÇÕES FINAIS}

Neste trabalho, apresentamos mecanismos de processamento de imagens que fazem uso de sistemas conexos. Heurísticas foram seguidas na elaboração de um processo de detecção de simetria e em um processo de segmentação de imagens. Vimos que os parâmetros precisam ser modificados para se adaptar às características de determinada imagem. Em um ambiente controlado, como na inspeção automática de uma determinada peça na linha de produção de uma indústria, por exemplo, os parâmetros podem ser ajustados para o processamento funcionar eficientemente.

Uma segmentação eficaz é altamente dependente da natureza da informação a ser extraída e das condições de iluminação do meio. Sem o devido controle do meio ou especificação do que é desejado, um processo de segmentação de imagens não será eficaz. Ou seja, há a necessidade de um conhecimento prévio das condições da imagem a ser segmentada. Então, resta a pergunta: Como tal modelo pode vir a ser aprimorado para tornar-se mais flexível a diferentes condições?

Por extrair os detalhes significativos de uma imagem, o processo de segmentação pode reduzir a quantidade de informação a ser processada para um valor próximo da informação mínima necessária. Portanto, a segmentação de imagens pode auxiliar numa etapa posterior de reconhecimento de padrões. Além disso, para que a informação relevante seja obtida e a irrelevante descartada, existe uma necessidade de reconhecimento de padrões no processo de segmentação.

Portanto, a segmentação e o reconhecimento de padrões podem compor um sistema híbrido iterativo, sendo que um filtra a informação que será utilizada pelo outro num processo realimentado; que pode ser mais eficiente do que a segmentação ou o reconhecimento de padrões funcionando separadamente. Enquanto o processo de segmentação atua como um filtro que pode reduzir a quantidade de informação a ser processada pelo reconhecedor de padrões, este é capaz de completar alguma informação que falte ou descartar padrões que surgem num contexto não esperado. Trabalhando cooperativamente, segmentação e reconhecimento decompõem a 
imagem em figuras que podem ser analisadas separadamente ou sintetizadas contextualmente por um sistema de inteligência artificial. Tal sistema teria a possibilidade de poder ser adaptativo, pois possui o poder associativo e sintético do reconhecimento de padrões combinado com o poder dissociativo e analítico da segmentação. Abstração, classificação e contextualização da informação são alternativas que passam a adquirir a possibilidade de adquirir certo grau viabilidade.

Uma outra sugestão para trabalho futuro seria utilizar uma rede neural, com aprendizado supervisionado, treinada para definir os valores dos parâmetros de modo que o processo de segmentação adapte-se às diferentes características de imagens. O usuário define os melhores parâmetros de segmentação para diversas imagens, oferecendo exemplos à rede neural, enquanto esta se encarrega de generalizar, encontrando uma relação funcional entre características intrínsecas à imagem (como, por exemplo, nível médio de tons de cinza, entropia, informação mútua entre elementos vizinhos, ou até mesmo simplesmente apenas a figura), e os parâmetros que serão adotados. Podemos imaginar que, realizado o aprendizado da rede neural, um sistema desse tipo seria capaz de segmentar imagens com diferentes granulações e iluminação. Teríamos, assim, um sistema adaptativo, capaz de ajustar seus parâmetros automaticamente para realizar a segmentação desejada. 


\section{Referências}

Assadi A., Eghbalnia H., Palmer, S. (2001). A learning theoretic approach to perceptual geometry in natural sciences. Neurocomputing, v. 38-40, p. 1077-1085.

Bow S.T. (1992). Pattern Recognition and Image Preprocessing. Marcel Dekker.

deMaris D. (2003). Analysis of dynamics and object recognition performance in coupled map networks. Neurocomputing, v. 52-54, p. 733-739.

deMaris D. (2002). Representation space in a network of coupled chaotic oscillators with modulated synchronization. Neurocomputing, v. 44-46, p. 365-372.

deMaris D. (2001). Synchronization opponent systems: Attractor basin transient statistics as a population code for object representation. Neurocomputing, v. 38-40, p. 547-554.

Fiedler-Ferrara N., Prado C. P. C. (1994). Caos: Uma Introdução. Edgard Blücher.

Gonzalez R.C., Woods R.E. (1992). Processamento de Imagens Digitais. Edgard Blücher.

Haykin S. (1994). Neural Networks: a Comprehensive Foundation. Macmillan/IEEE Press.

Hernandez E.D. M., Lee G., Farhat N.H. (2003). Analog realization of arbitrary onedimensional maps. IEEE Transactions on Circuits and Systems - I: Fundamental Theory and Applications, v. 50, p. 1538-1547.

Kaneko K. (1986). Collapse of Tori and Genesis of Chaos in Dissipative Systems. World Scientific.

Kaneko K. (1992). Overview of coupled map lattices. International Journal of Bifurcation and Chaos, v. 2, p. 279-282.

Kaneko K. (1993). Theory and Applications of Coupled Map Lattices. John Wiley \& Sons.

Kaneko K., Tsuda I. (2000). Complex Systems: Chaos and Beyond. Springer.

Leeuwen C. van, Steyvers M., Nooter M. (1997). Stability and intermittency in large-scale coupled oscillator models for perceptual segmentation. Journal of Mathematical Psychology, v. 41, p. 319-344.

Monteiro L.H.A. (2003). Sincronismo global e parcial em redes de osciladores de fase. Anais do II Congresso Temático de Dinâmica, Controle e Aplicações (São José dos Campos, SP), v. 1, p. 1145-1172.

Monteiro L.H.A., Canto N.F.C., Chauí-Berlinck J.G., Orsatti F.M., Piqueira J.R.C. (2003). Global and partial synchronism in phase-locked loop networks. IEEE Transactions on Neural Networks, v. 14, p. 1572-1575. 
Monteiro L.H.A. (2005). Estudos Analíticos em Redes Neurais e Redes de Telecomunicações. Tese de Livre Docência. EPUSP.

Monteiro L.H.A. (2006). Sistemas Dinâmicos. Livraria da Física.

Nicolini L.E., Prado P.P.L. (2002). Reconhecimento de objetos contidos em imagens através de redes neurais. Revista de Ciências Exatas de Taubaté, v. 5-8, p. 77-88.

Ogata K. (2003). Engenharia de Controle Moderno. Prentice Hall.

Oliveira R. (2004). Mapas Acoplados e Aplicações: Processamento de Imagens, AutoOrganização e Processamento Simbólico. Tese de Doutorado. EPUSP.

Oliveira R., Monteiro L.H.A. (2002). Symmetry detection using global-locally coupled maps. Lecture Notes in Computer Science, v. 2415, p. 75-80.

Oliveira R., Monteiro L.H.A. (2004). Sincronismo de mapas em redes regulares aleatórias. $3 o$ Congresso Temático de Dinâmica, Controle e Aplicações, v. 1, p. 739-754. UNESP.

Rizzo, G. J., Oliveira, R., Monteiro L.H.A. (2005). Uso de redes de mapas acoplados para controle de posição de peças simétricas. 4o Congresso Temático de Dinâmica, Controle e Aplicações, v. 1, p. 1575-1578. UNESP.

Ruiz-del-Solar J. (1998). Texture segmentation using self-organizing maps. Neurocomputing, v. 21, p. 7-18.

Sánchez J.R., López-Ruiz, R. (2005). A method to discern complexity in two-dimensional patterns generated by coupled map lattices. Physica A, v. 355, p. 633-640.

Sansão J.C. (2003). Aspectos de Mapas Caóticos Acoplados para Processamento de Informações. Dissertação de Mestrado. INPE.

Singer W., Gray C.M. (1995). Visual feature integration and the temporal correlation hypothesis. Annual Review of Neuroscience, v. 18, p. 555-586.

Strogatz S.H. (1994). Nonlinear Dynamics and Chaos: With Applications to Physics, Biology, Chemistry and Engineering. Addison-Wesley.

Wang X.F., Chen G. (2002). Synchronization in small-world dynamical networks. International Journal of Bifurcation and Chaos, v. 12, p. 187- 192.

Zhao L., Macau E.E.N. (2001). A network of dynamically coupled chaotic maps for scene segmentation. IEEE Transactions on Neural Networks, v. 12, p. 1375-1385. 